\title{
UN MARCO CONSTITUCIONAL PARA LOS TRATAMIENTOS MÉDICOS DE NIÑOS, NIÑAS Y ADOLESCENTES ${ }^{1}$
}

\author{
UN MARCO CONSTITUCIONAL PARA LOS TRATAMIENTOS \\ MÉDICOS DE NIÑOS, NIÑAS Y ADOLESCENTES ${ }^{1}$
}

José Manuel DíAZ de VALdés J.2, 3

\begin{abstract}
RESUMEN: Los problemas asociados al consentimiento para los tratamientos médicos de los niños son conflictos netamente constitucionales vinculados a la exigibilidad y los límites de los derechos fundamentales de los niños, así como a los derechos y deberes de los padres. Diversos derechos del niño pueden verse afectados por tratamientos médicos (e.g., vida, privacidad) por lo que tales situaciones deben sujetarse a los límites comunes a las restricciones a derechos fundamentales. La sustitución de la voluntad del menor por sus padres (no por sus representantes legales) es constitucionalmente legítima en la medida que se someta a ciertas limitaciones sustanciales (e.g., principio evolutivo, interés superior del menor) y procedimentales (e.g., derecho del niño a ser informado). Se proponen reglas para resolver desacuerdos entre el niño, sus padres y los médicos.
\end{abstract}

Palabras clave: tratamiento médico, derechos de los niños, interés superior del niño, autonomía corporal, deberes de los padres.

ABSTRACT: Consent to medical treatment in children brings up conflicts that are constitutional in nature, relating to the enforcement and limits of the fundamental rights of the children, as well as to the parents' rights and duties. Several children' rights might be interfered with by medical treatments (e.g., right to life, privacy), therefore such situations should be subject to the limits common to all interferences with fundamental rights. The substitution of the child's will by his/her parents' (but not by his/her legal representatives) is constitutionally acceptable insofar as it is subject to substantial (e.g., evolving principle; best interest of the child) and procedural limitations (right of the child to be informed). Rules are proposed to address disagreements between children, their parents and doctors.

Key words: medical treatment, children's rights, best interest of the child, body autonomy, parents' duties.

\footnotetext{
${ }^{1}$ Este artículo se inserta dentro de un proyecto de investigación más amplio, y por tanto debe considerarse conjuntamente con el trabajo "Tratamientos Médicos en Menores de Edad: Situación Actual y Claroscuros del Proyecto de Ley sobre los Derechos y Deberes en Relación a la Atención en Salud" (en prensa), ponencia en las XXXVIII Jornadas Chilenas de Derecho Público, organizadas por la Universidad de Concepción.

2 Director de Investigación de la Facultad de Derecho de la Universidad del Desarrollo. Profesor de Derecho Constitucional de la Universidad del Desarrollo y de la Pontificia Universidad Católica de Chile. Licenciado en Derecho y Magíster en Derecho Público de la Pontificia Universidad Católica de Chile. Master of Laws de la Universidad de Cambridge. Master of Laws de la Universidad de Harvard. Doctorando de la Universidad de Oxford.

${ }^{3}$ Quisiera agradecer la acuciosa labor de investigación de mis ayudantes, señor Nicolás Enteiche Rosales y señorita Paulina Lobos Herrera, así como los valiosos comentarios de los profesores José Francisco García García y Sergio Verdugo Ramírez.
} 
Ser niño no es ser "menos adulto", la niñez no es una etapa de preparación para la vida adulta. La infancia y la adolescencia son formas de ser persona y tienen igual valor que cualquier otra etapa de la vida4

\section{INTRODUCCIÓN}

La situación general de los niños, niñas y adolescentes (en adelante indistintamente "niños") en el derecho ha sufrido importantes transformaciones en las últimas décadas. Es así como la antigua visión que concebía al niño como una suerte de individuo incompleto, o en proceso hacia la plena personificación, ha sido progresivamente reemplazada por el reconocimiento de su carácter de sujeto cabal de derechos ${ }^{5}$. Consecuencialmente, en materia de tratamiento médico, poco a poco, y gracias a la influencia del derecho comparado, hemos ido comprendiendo que el niño tiene mucho que decir, e incluso que decidir.

No obstante lo anterior, una perspectiva arcaica sobrevive en nuestro ordenamiento jurídico, el cual continúa considerando a los niños simplemente como incapaces de otorgar un consentimiento válido, incluso respecto de decisiones tan personales como las que atañen su salud. Si bien Chile ha adoptado diversos instrumentos internacionales que deberían conducir a un cambio en esta materia (e.g., Convención Sobre los Derechos del Niño, en adelante la "Convención"; Declaración de los Derechos del Niño, en adelante "DDN"), a la fecha esta vía ha demostrado ser completamente insuficiente para provocar la necesaria evolución. Peor aún, frente al atraso de la normativa y la dogmática jurídica, los médicos han optado por desarrollar ciertas prácticas que ignoran las normas legales vigentes.

Evidentemente, la situación descrita es insatisfactoria y confusa. Aquella no define con claridad ni justicia los derechos, deberes y obligaciones de los niños, sus padres, médicos tratantes y el Estado. Si bien existen diversos proyectos de ley sobre estas materias ${ }^{6}$, creemos que parte insoslayable del problema se encuentra en la ausencia de un marco teórico constitucional aplicable en la especie. En efecto, resulta evidente que nos encontramos frente a un tópico íntimamente ligado a principios, derechos, y en general, a contenidos constitucionales, en particular a los derechos fundamentales. Sin embargo, la doctrina constitucional se ha mantenido al margen, cuestión que ha redundado en que el extraordinario desarrollo de los derechos fundamentales en los ordenamientos jurídicos contemporáneos, sus exigencias, estándares de control y demás construcciones doctrinarias, no hayan logrado impregnar la situación jurídica de los niños.

\footnotetext{
${ }^{4}$ Cillero (1999) p. 4.

5 Berro (2001) p. 46; Cillero (1999) Sección III. b); Baeza (2001) p. 359, y Aguilar (2008) p. 225.

${ }^{6}$ Boletín 2727-11; Boletín 3690-11; Boletín 4201-11; Boletín 4398-11; Boletín 4270-11; Boletín 427111, y Boletín 5890-11. Algunas características comunes a la generalidad de estos proyectos son las siguientes: i) reconocimiento de mayores derechos a los menores de edad, particularmente a partir de los 14 años; ii) se mantiene la importancia del representante legal en la decisión de tratamientos médicos, y iii) no se logra aclarar suficientemente la relación menor-padres-médicos y las formas de superar desacuerdos entre ellos.
} 
En este contexto, el presente artículo intenta bosquejar un marco teórico constitucional focalizado en la necesidad de garantizar la vigencia efectiva de los derechos fundamentales involucrados. Aquel debe ser capaz de insertar armónicamente la olvidada situación de los niños frente a los tratamientos médicos en la dogmática constitucional contemporánea. Adicionalmente, es necesario que entregue orientaciones prácticas precisas acerca quién debe decidir; bajo qué circunstancias; con cuáles excepciones; cuándo debe intervenir el Estado, y cómo debe procederse si existen conflictos.

Para ello comenzaremos con un breve diagnóstico crítico de la situación jurídica actual del tratamiento médico de los niños. Luego intentaremos esbozar nuestra propuesta de marco constitucional, elaborado sobre la base de las normas y principios actualmente vigentes $^{7}$. Principiando por la identificación de la naturaleza jurídica-constitucional de los niños bajo nuestra Constitución Política (“CP”), seguiremos con la singularización de los derechos fundamentales más frecuentemente involucrados en los tratamientos médicos. A continuación abordaremos los fundamentos constitucionales de la facultad paterna de intervenir en estas circunstancias, identificando también sus límites o condicionamientos, así como ciertos principios y criterios aplicables en la materia. Destacaremos luego la importancia y los derechos del niño en el procedimiento que debe utilizarse en estas situaciones, para finalizar ofreciendo reglas concretas acerca de cómo solucionar los conflictos que surjan entre los niños, sus padres y los médicos tratantes.

Una aclaración final. Este artículo no intenta desconocer o prescindir de los derechos y deberes de los padres, y en general de la familia, en relación a los niños. Tampoco es nuestra intención defender una visión hiperindividualista de los derechos de los niños ${ }^{8}$. Por el contrario, consideramos que la conservación del rol paterno y familiar, así como una noción socialmente contextualizada de los derechos de los niños, exigen su reformulación sobre bases más sólidas (i.e., constitucionales en lugar de simplemente legales), así como la mayor definición de sus limitaciones y formas de control. El requisito sine qua non de tal reformulación, sin embargo, es la real y honesta aquilatación de los derechos de los niños, exigencia que aún estamos lejos de cumplir, y a la cual este artículo pretende colaborar.

\section{DIAGNÓSTICO9}

En la actualidad, el tratamiento médico de los niños en Chile está determinando por tres fuentes principales: el derecho civil, el derecho internacional sobre derechos humanos y la práctica médica.

\footnotetext{
7 Si bien nos parece indudable que ciertas reformas constitucionales y legislativas puedan ser de gran relevancia para el perfeccionamiento y precisión del marco propuesto, pensamos que las normas y principios jurídico-constitucionales actualmente vigentes son suficientes para, a lo menos, sentar las bases y características fundamentales de dicho marco. En otras palabras, nuestro ordenamiento jurídico vigente es incompatible con la realidad del tratamiento médico de los niños en Chile, y es suficiente para exigir e imponer cambios estructurales y sistematizados a tal situación.

${ }^{8}$ GLENDON (1998).

${ }^{9}$ Esta sección constituye una síntesis de un fragmento de la ponencia presentada en las XXXVIII Jornadas Chilenas de Derecho Público. Díaz de VALDÉs (en prensa).
} 


\section{El Derecho CiVIL}

El Derecho Civil ha regulado la situación jurídica de los niños mediante tres instituciones fundamentales: la capacidad, la autoridad paterna y las tutelas y curatelas.

La capacidad es la "aptitud legal para adquirir derechos y ejercitarlos"10. Los niños carecen de ella (artículo 1447, inciso 3º del Código Civil), por lo que la regla básica en la materia que nos ocupa es que los niños no pueden decidir libremente acerca de los tratamientos médicos que se practiquen en su cuerpo. Surge entonces la interrogante de quién decide por ellos. La autoridad paterna ${ }^{11}$ permite dar respuesta a la última dificultad planteada, radicando en los padres las decisiones sobre los tratamientos médicos de sus hijos. En efecto, la autoridad paterna se fundamenta en la filiación, e incluye la obligación de conservar la vida y velar por la salud del hijo ${ }^{12}$, cuestión que necesariamente supone la decisión acerca de los tratamientos médicos que se le apliquen. A falta de los padres, el Derecho Civil contempla el nombramiento de un tutor o curador del niño, el cual asume las responsabilidades de administrar, conservar, reparar y cultivar los bienes del pupilo (artículo 391 del CC), las que comúnmente se han extendido al cuidado de su persona.

\section{EL DERECHO INTERNACIONAL}

Durante el siglo XX tuvieron lugar dos fenómenos relevantes en el Derecho Internacional: la preocupación especial por los niños llevó a la celebración de diversos instrumentos internacionales especializados ${ }^{13}$, y se produjo un profundo cambio de paradigma en el estatus de los niños, quienes pasaron de ser meros objetos de protección, a constituirse en verdaderos sujetos de derechos ${ }^{14}$. Las consecuencias de dicho cambio han sido vastas, obligando a la reformulación de concepciones profundamente arraigadas, tales como los derechos de los padres "sobre" los niños.

El Derecho Internacional, sin embargo, ha sido insuficiente para resolver los problemas jurídicos generados por el tratamiento médico de niños en nuestro país. Ello debido a que: i) aquel tiende a constituir un "mínimo" universal y general más que un estándar realmente adecuado y preciso de protección; ii) aquel es raramente aplicable en forma directa y autónoma en el ámbito interno; iii) sus contenidos y principios han sido incorporados solo fragmentariamente a nuestra legislación (destaca a este respecto la recepción del principio del interés superior del niño), y iv) su potencial aplicación disminuye debido a la falta de una teoría constitucional coherente en la materia que de unidad a las normas internas e internacionales.

\footnotetext{
10 AlESSANDRI et al. (1998) p. 248.

11 "conjunto de derechos y obligaciones de contenido eminentemente moral, existente entre padres e hijos" RAMOS (2001) p. 423, o bien "la que organiza la familia y a la cual corresponde la crianza, educación y establecimiento de los hijos, autoridad que más que derechos tiene obligaciones para la protección de estos” Claro (1925) p. 35. Cabe destacar que el concepto de autoridad paterna ha ido evolucionando en el tiempo, cuestión que quedó en evidencia durante la discusión de la Ley No 19.585. Sin embargo, se mantiene la diferencia con la patria potestad, ya que esta última se refiere exclusivamente a la dimensión patrimonial.

12 PAVEZ (2004) pp. 73-74.

13 E.g., Declaración de los Derechos del Niño, Convención sobre los Derechos del Niño.

14 Esta idea es casi un lugar común en la doctrina revisada, e.g., BERro (2001) p. 46; CiLlero (1999) Sección III. b); BAEZA (2001) p. 359, y AgUiLAR (2008) p. 225.
} 


\section{LA PRÁCTICA MÉDiCA}

Al margen de las instituciones y normas jurídicas ya mencionadas, los médicos han venido desarrollando una práctica propia (en ocasiones reflejada en protocolos) sobre la base de tres nociones fundamentales: los principios básicos de la bioética, el consentimiento informado y la capacidad natural.

Los cuatro principios básicos de la bioética ${ }^{15}$, de origen anglosajón y creciente $-s i$ bien discutida- aplicación mundial, son los siguientes: i) la autonomía o "capacidad de la persona competente para decidir, por sí misma, en diversas materias atinentes a su salud y, por ende, a sus condiciones de vida"16 17; ii) la Beneficencia u obligación general "de hacer el bien" 18 , de favorecer, maximizando siempre los posibles beneficios ${ }^{19}{ }^{20}$; iii) la No maleficencia o no hacer daño y evitar posibles menoscabos ${ }^{21}$, y iv) la Justicia, entendida en forma general ("dar a cada uno lo suyo"22 2324 ) o más específica (e.g., obligación de "procurar los recursos suficientes para que todos tengan acceso fácil a la salud, cualquiera sea su situación social o económica o el lugar en que se encuentre”25).

En cuanto al consentimiento informado, este obedece a una concepción más horizontal y menos parternalista de la relación entre médico y paciente ${ }^{26}$, cuya "esencia no es otra cosa que considerar que las decisiones en salud, para ser moralmente acepta-

15 La obra clásica a este respecto es BEAUCHAMP y CHILDRESS (2001) pp. 57 y ss., la que a su vez es tributaria del famoso Informe Belmont: The National Commission for the Protection of HuMAN Subjects of Biomedical ANd Behavioral Research (1979) part. B. Cabe destacar, sin embargo, que estos principios no son universalmente aceptados, gozando de mayor acogida en el mundo anglosajón. Hay quienes los rechazan como tributarios de una moral utilitarista. Otros los aceptan, pero contextualizados en ciertos principios o marcos éticos distintos a los originales. También existen autores que los consideran inútiles o vacíos, e.g., UGARTE (2006) pp. 356-357; ROA (1998) pp. 167 y ss., y CICCONE (2005) pp. 39 y ss.

16 VÁsquez (2002) p. 53; Beauchamp y Childress (2001) pp. 57 y ss; The National Commission for the Protection of Human Subjects of Biomedical and Behavioral Research (1979) Part B.1; UGARTE (2006) p. 356, y BRUgueras (2004) p. 14.

17 Supone voluntariedad, información y capacidad, así como la protección de quienes presentan su autonomía disminuida (e.g., menores de edad). Bórquez et al. (2004) pp. 1243 y 1244, y The NATIONAL Commission for the Protection of Human Subjects of Biomedical and Behavioral Resear$\mathrm{CH}$ (1979) part. B.1

18 UGARTE (2006) p. 356.

19 Brugueras (2004) p. 16; CiCCOne (2005) p. 39; Roa (1998) p. 168, y The National Commission for the Protection of Human Subjects of Biomedical and BehaVioral Research (1979) part. B.2.

20 Podría también extenderse a promover el bien, así como prevenir y rechazar el mal, BEAUCHAMP y CHILDRESS (2001) pp. 113 y ss.

21 Beauchamp y Childress (2001) pp. 165 y ss. y The National Commission for the Protection of Human Subjects of Biomedical and BeHaVioral RESEARCH (1979) part. B.2.

22 Esta clásica definición se le ha tradicionalmente atribuido a Ulpiano, sin embargo, su origen sería griego. WiLliams (1999) p. 274.

23 The National Commission for the Protection of Human Subjects of Biomedical and BeHAVIORAL RESEARCH (1979) part. B.3 y Ciccone (2005) p. 39

24 Debe también recordarse que tal máxima presenta significados diversos para distintas escuelas filosóficas. BEAUCHAMP y CHILDRESS (2001) pp. 225 y ss.

25 ROA (1998) p. 165.

26 E.g., Burdiles (2004) p. 97; PaCheco (2001) pp. 156 y 157 y Murúa (2000) pp. 7 y 8. 
bles deben ser decisiones autónomas tomadas por los afectados por ellas" 27 . En otras palabras, como solo el paciente tiene derecho a decidir sobre su cuerpo, el médico no puede implementar un tratamiento sin que concurra su voluntad. A su vez, para que dicha expresión de voluntad tenga un contenido real, debe entregársele al paciente la información necesaria para adoptar la decisión que le parezca más conveniente. Tal información debe ser veraz, lo más completa posible, pero explicada en forma comprensible para el paciente. Lo que prima en esta materia es la realidad del consentimiento por sobre las formas utilizadas $28,29$.

Finalmente, la práctica médica ${ }^{30}$ ha desarrollado un concepto distinto a la capacidad legal, denominado capacidad natural o competencia ${ }^{31}$. Mientras la primera se determina rígidamente en razón de la edad, la segunda atiende a la madurez real y comprobable de un paciente determinado en el contexto de la decisión concreta que debe adoptar. En otras palabras, la capacidad natural se determina siempre caso a caso, y no necesariamente coincidirá con la capacidad legal ${ }^{32} 33$. Ahora bien, si el médico comprueba que un niño posee dicha capacidad natural, su consentimiento al tratamiento adquiriría plena validez, aun por sobre la voluntad de sus padres o representantes legales. Algunos criterios a considerar para determinar la competencia del niño son ${ }^{34}$ : i) las capacidades de comunicarse; entender la información; razonar, deliberar, tener y aplicar una serie de valores o una concepción de lo bueno; ii) la capacidad de adoptar una decisión, lo que supone dimensionar las distintas alternativas y las consecuencias asociadas a cada una de ellas, así como la libertad suficiente para optar; iii) la comprensión intelectual y emotiva del tratamiento y de sus efectos ${ }^{35}$; iv) la edad, pero solo a modo referencial en relación al desarrollo psíquico, valórico y emocional esperable.

\section{Conclusión del Diagnóstico}

El marco jurídico-práctico existente en materia de consentimiento de niños al tratamiento médico no es en absoluto satisfactorio, ya que tratándose de un tema que afecta derechos constitucionales (sección IV subsiguiente), resulta inaceptable que no exista un marco jurídico basado primeramente en la CP. Más aún, es evidente que el tratamiento médico es una interferencia con los derechos fundamentales del niño, y

\footnotetext{
27 BÓRQUEZ et al. (2004) p. 1243.

${ }_{28}^{2}$ Por ejemplo, PACHeCo (2001) p.157, y Burdiles (2004) p. 97.

${ }^{29}$ En todo caso, cabe destacar que este principio no es absoluto. Las excepciones normalmente aceptadas son aquellas que dicen relación con las urgencias médicas (no hay posibilidad material de esperar el consentimiento informado del paciente); la protección de la salud pública (e.g., en caso de epidemias los pacientes pueden ser tratados aún contra su voluntad); o la imposibilidad de entregar el consentimiento (e.g., inconsciencia, incapacidad mental, eventualmente la minoría de edad).

30 Maglio (2001) p. 38.

31 Muy extendida en la doctrina revisada, e.g., BERRO (2001) p. 46; SANCHO (2004) p. 20; MAGLIO (2001) p. 38, y BÓRQUEZ et al. (2004) p. 1244.

32 SANCHO (2004) pp. 20 y ss.

33 Esta doctrina se asemeja también al concepto de "menor maduro" desarrollado en ciertas jurisdicciones. BERRO (2001).

34 BRUgERAS (2004) p. 19 y los autores que ahí se invocan.

35 SANCHO (2004) p. 21.
} 
como tal requiere de un tratamiento doctrinario que lo sujete a las reglas generales acerca de la limitación de tales de derechos (e.g., establecimiento por ley, proporcionalidad). En cuanto al derecho internacional, si bien es útil, tampoco es suficiente por las razones ya expresadas. Finalmente, el desarrollo de una práctica médica ajena a la legislación vigente demuestra en toda su amplitud la inconsistencia de la situación actual y la necesidad de un cambio radical ${ }^{36}$.

\section{PUNTO DE PARTIDA}

El punto de partida de nuestro análisis es la naturaleza jurídica constitucional del niño y las consecuencias que se derivan de ella. En efecto, no cabe duda que el niño es una persona ${ }^{37}$. En términos constitucionales, no se trata de un semiadulto o de un futuro-adulto: el niño es una persona a cabalidad a quien no falta nada -ni edad, ni discernimiento, ni madurez- para gozar de las prerrogativas de $\operatorname{tal}^{38}$. Es así como nuestra Constitución le reconoce una serie de derechos que emanan de esa naturaleza de persona humana $^{39}$ (artículo $5^{\circ}$ ). Más aún, lo hace en el mismo pie que a los adultos, ya que declara expresamente, en su primera frase, que las personas nacen libres e iguales en dignidad y derechos (artículo $1^{\circ}$ inciso 1), y agrega que los derechos constitucionales se reconocen a toda persona (artículo 19 inciso $1^{\circ}$ ), sin contemplar distinciones de edad.

En otras palabras, nuestra CP resuelve expresamente dos cuestiones altamente discutidas en la doctrina contemporánea especializada en estas materias: cuál es el origen de los derechos de los niños, y si se trata realmente de derechos y no de meros intereses protegidos o del resultado del cumplimiento de ciertas obligaciones jurídicas o morales de otros sujetos ${ }^{40}$.

Algunos corolarios de lo anterior son los siguientes:

1. Los adultos no prefieren a los niños en el ejercicio de sus derechos.

2. Las restricciones a los derechos de los niños deben necesariamente someterse a las normas generales en la materia (e.g., establecidas por ley, finalidad legítima, medios apropiados, proporcionalidad).

3. El niño es, ante todo, un sujeto de derechos y no solo un incapaz jurídico ${ }^{41}$.

\footnotetext{
36 En esta misma línea, cabe observar que los protocolos médicos, por respetables y útiles que sean, no revisten la jerarquía normativa suficiente para legitimar y lidiar con limitaciones a derechos fundamentales. 37 El Tribunal Constitucional ha señalado que hay persona incluso desde la concepción. TRIBUNAL CONSTITUCIONAL (2008) rol No 740, considerando Quincuagésimooctavo. Diversos tratados internacionales apuntan en la misma dirección de reconocer al niño en cuanto persona, ya sea en sus articulados o en sus preámbulos (que si bien no son estrictamente vinculantes, constituyen marcos interpretativos de relevancia), e.g., artículo $1^{\circ}$ de la Convención y Preámbulo de la Declaración de Derechos del Niño. El Código Civil también reconoce a los niños como persona en su artículo 55.

38 Cillero (1999) Sección II (habría sido uno de los propósitos de la Convención), y CORTE INTERAMERICANA DE DERECHOS Humanos (2002) opinión consultiva OC-17/2002.

39 FERNÁNDEZ (2008) Sección II.

40 Cillero (1999) Sección III b) afirma que la Convención consagró esta idea.

41 Corte Suprema (2006) rol No 6553-2005, considerando Tercero.
} 
4. Los derechos de los niños se ejercen, al igual que los de los adultos, frente a todos, incluidos Estado, sociedad, individuos e incluso sus padres ${ }^{42}$ (artículo $6^{\circ}$ de la CP).

5. Al igual que en el caso de los adultos, se trata de derechos irrenunciables, indelegables e imprescriptibles.

\section{DERECHOS INVOLUCRADOS}

El tratamiento médico de los niños, en particular cuando no es consentido, se vincula a una serie de derechos protegidos por la CP. Revisemos en forma breve los principalmente involucrados ${ }^{43}$.

\section{DERECHO A LA VIDA}

(Artículo $19 \mathrm{~N}^{\circ} 1$ de la CP; artículo $4^{\circ}$ de la Convención Americana sobre Derechos Humanos, en adelante "CADH"; artículo $3^{\circ}$ de la Declaración Universal de Derechos Humanos, en adelante "DUDH”, y artículo 6o del Pacto Internacional de Derechos Civiles y Políticos, en adelante "PIDCP”).

El derecho a la vida está presente en el tratamiento médico de diversas formas. Primero, en su sentido más natural y obvio, i.e., el derecho a conservar la vida ${ }^{44}$. La implementación del tratamiento médico adecuado puede ser determinante para estos efectos, al punto de primar por sobre otras consideraciones jurídicamente relevantes (e.g., el derecho y deber de los padres de velar por el cuidado de los hijos; la voluntad del niño en la conservación de su vida; cuestionamientos religiosos). Debemos recordar a este respecto que en nuestro país, al margen de las diversas doctrinas sobre el punto, la jurisprudencia ha consistentemente reafirmado una suerte de "jerarquía superior de hecho" del derecho a la vida, cuyo carácter de "derecho fundante de todos los demás" 45

42 No analizaremos todos los derechos que eventualmente se pueden ver interferidos o vulnerados con ocasión de un tratamiento médico no consentido, sino solo aquellos más directa o posiblemente afectados. Entre los no tratados especial mención merece el libre e igualitario acceso a las prestaciones de salud (artículo $19 \mathrm{~N}^{\circ} 9$ de la CP; artículo 24 de la Convención; artículo 25 de la DUDH; artículo $4^{\circ}$ de la DDN, y artículo 12 del Pacto Internacional de Derechos Económicos, Sociales y Culturales), ya que nos parece que su aplicación en la materia es discutible. Si bien la literalidad del texto constitucional permitiría su invocación (FERNÁNDEZ (2008) Sección IV), nos parece que la mayoría de la doctrina revisada (EVANS (1999) pp. 316 y ss.; CEA (2004) pp. 300 y ss., y Silva (2008) pp. 129-131) y las actas de la Comisión de Estudios de la Nueva Constitución (principalmente sesiones 187a $, 190^{\mathrm{a}}, 192^{\mathrm{a}}$ y $193^{\mathrm{a}}$ ), denotan que el derecho en comento tendría un contenido diverso, i.e., imponer al Estado directamente, o a través de los privados, la obligación de crear y mantener un sistema adecuado de protección de la salud. Esto difiere de la obligación de eliminar toda clase de obstáculos (i.e., la voluntad paterna) para acceder a las prestaciones de salud, cual sería el contenido relevante para nuestro estudio. COMISIÓN DE ESTUDIO DE UNA NUEVA CONSTITUCIÓN (1976)

43 E.g., Ugarte (2006) p. 117; Silva (2006) Tomo VI p. 47, y EVANS (1999) p. 113. Figueroa (2008) pp. 268-270 parece apartarse, al menos parcialmente, de esta línea.

44 Tribunal CONSTiTUCIONAL (2008) rol No 740.

45 En materia de transfusiones de sangre a Testigos de Jehová, CORTE DE APELACIONES DE COPIAPÓ (2008) rol No 230-2008, considerandos Segundo, Tercero y Quinto; CoRTE DE APELACIOnes DE RANCAGUA (2008) rol No 1034-2007, considerando Primero, y CORTE DE ApElaCiOnes de SAN Miguel (2008) rol No 
le hace primar normalmente por sobre otros derechos (e.g., casos de transfusiones de sangre a Testigos de Jehová, huelgas de hambre de prisioneros ${ }^{46}$ ).

Segundo, nos parece que los tratamientos médicos se relacionan directamente con el concepto de calidad de vida, ya que muchos de ellos suponen interferencias severas para el paciente, así como consecuencias o secuelas que pueden ser permanentes o al menos duraderas en el tiempo.

\section{DERECHO A LA INTEGRIDAD FÍSICA Y PSÍQUICA \\ (Artículo $19 \mathrm{~N}^{\circ} 1$ de la CP y artículo $5^{\circ}$ de la $\mathrm{CADH}$ )}

Este es el derecho más directamente involucrado en los tratamientos médicos. Sabemos que la integridad física dice relación no solo con la preservación de los componentes del cuerpo humano ${ }^{47}$, sino también con el señorío sobre el propio cuerpo ${ }^{48}$. Ello supone, como regla general, que no se puede realizar una intervención médica en el cuerpo de un paciente sin contar con su beneplácito.

A nuestro parecer, en esta materia existe notoria cercanía al principio de autonomía desarrollado por la práctica médica, ya antes comentado en este trabajo.

Indisolublemente ligada a lo anterior aparece la integridad psíquica, entendida como la conservación de la salud e identidad moral, mental y espiritual de la persona ${ }^{49}$. La relación entre cuerpo y mente es innegable, particularmente cuando estamos frente a tratamientos largos o particularmente invasivos.

Este es un derecho que potencia con especial fuerza la posición del niño frente al tratamiento médico. En efecto, cuando la ley entrega la decisión definitiva acerca de la aplicación de un tratamiento médico a los padres o representantes de un niño, se corre un riesgo real de violentar los deseos del paciente. Si bien esta puede ser una solución necesaria en determinadas circunstancias, no se puede menospreciar jamás el impacto que un tratamiento no consentido puede causar sobre la psiquis del niño. Y es que la intervención heterónoma sobre el propio cuerpo es una forma particularmente intolerable de violencia.

104-2008, considerandos Noveno a Decimoséptimo. Para más información respecto a casos anteriores, RETAMALES (2003). En materia de huelgas de hambre de prisioneros, CORTE DE APELACIONES DE RANCAGUA (2002) rol No 2292-2002, Segundo a Cuarto; CoRTE DE ApelaCiOnes De TemuCo (2007) rol No 18482007, considerando Cuarto; CORTE De Apelaciones de SANTIAgO (1994) rol No 846-1994, considerando Segundo y Tercero. No obstante todo lo anterior, el fallo de la CORTE DE APELACIONES DE PUERTO MONTT (2008) rol No 172-2008, considerandos Tercero y Cuarto, podría representar un cambio en la posición tradicional de los tribunales chilenos en relación a la jerarquía o valor especial del derecho a la vida.

46 SILVA (2006) p. 56-57.

47 EVANS (1999) pp. 123 y ss. y SiLVA (2006) p. 60.

48 Molina (2006) p. 200; Silva (2006) pp. 56-58 y Cea (2004) pp. 94-95 y 113.

49 Corte de Apelaciones de Santiago (1993) rol No 983-1993, considerando Séptimo (sentencia confirmada por la Corte Suprema). 


\section{PRIVACIDAD}

(Artículo $19 \mathrm{~N}^{\circ} 4$ de la CP; artículo 16 de la Convención; artículo 12 de la DUDH, y artículo 17 del PIDCP)

Entendemos por privacidad "aquella zona que el titular del derecho no quiere que sea conocida por terceros sin su consentimiento" 50 , o bien, "el derecho a vivir, tanto como uno desee, protegido de la publicidad" 51 . Este derecho permite imponer un límite al mundo externo para desarrollar la propia personalidad ${ }^{52}$.

Si bien existen diversos criterios para determinar qué dimensiones de la vida de una persona quedan protegidas por la privacidad, ciertos elementos son claramente privados. Es así como la Ley $\mathrm{N}^{\circ} 19.628$ sobre Protección de la Vida Privada reconoce expresamente que algunos datos personales tienen el carácter de "sensible", característica que refuerza su calidad de privados y la excepcionalidad de su revelación. Tales serían "aquellos datos personales que se refieren a las características físicas o morales de las personas o a hechos o circunstancias de su vida privada o intimidad", ofreciendo como ejemplo "los estados de salud físicos o psíquicos" (artículo 2o letra g)). A ello debemos agregar las normas procesales y penales que reconocen el privilegio de confidencialidad de la relación entre médico y paciente ${ }^{53}$.

En consecuencia, podemos afirmar que en Chile todos los datos e informaciones relativos a la "vida sanitaria" de una persona, sus enfermedades, tratamientos, relaciones clínicas, fichas, etc., son "reforzadamente" privados ${ }^{54}$.

En el caso de los niños, nuevamente estamos frente a una excepción a la regla general, ya que los padres son normalmente informados a profundidad de la situación de salud de sus hijos. Si bien esto puede ser necesario y legítimo, no puede asumirse como tal sin mayor análisis, ya que la evidente afectación del derecho a la privacidad del niño exige que tal facultad de los padres sea debidamente fundamentada, tanto a nivel abstracto como en el caso concreto.

Finalmente, destacamos que el derecho a la privacidad en otros países, particularmente anglosajones, se entiende en forma más amplia, al punto de incluir también la facultad de decidir sobre materias que afecten al sujeto y a su cuerpo. Constituiría así

\footnotetext{
50 Comisión Europea de Derechos Humanos (1976) X v. Island, p. 87.

51 FELDMAN (2002) p. 511 señala que "la privacidad, en el sentido de un espacio protegido para adoptar decisiones dentro del cual un individuo o grupo de individuos, es libre de la interferencia de otros, ayuda a producir las condiciones en la cuales la libertad de elección puede ser ejercida libremente”.

52 E.g., artículo 160 del Código de Procedimiento Civil y artículo 303 del Código de Procedimiento Penal.

53 Couceiro y Heredia (2007) p. 72. Considérese también que el Código Sanitario, en su artículo 134, consagra el carácter de reservado de "Los registros, libros, fichas clínicas (...) salvo para las autoridades judiciales del Ministerio Público y para el Servicio Nacional de Salud”. Del mismo modo, la Ley N 19.628 sobre Protección de la Vida Privada modificó el artículo 127 del Código Sanitario, estableciendo que: "Las recetas médicas y análisis o exámenes de laboratorios clínicos y servicios relacionados con la salud son reservados. Solo podrá revelarse su contenido o darse copia de ellos con el consentimiento expreso del paciente, otorgado por escrito. (...)".

54 Feldman (2002) pp. 511 y ss. y PAVEz (2004) pp. 39 y ss. En EE.UU., la Corte Suprema ha reconocido un derecho a la privacidad implícito en su constitución, el cual ha servido de fundamento conceptual a cuestiones tales como el derecho al aborto y a la autonomía en materia de relaciones sexuales. Para una revisión sintética de esta línea jurisprudencial, CHOPER (2001).
} 
una base alternativa a la autonomía o señorío sobre el propio cuerpo, la cual se ha utilizado para fundamentar pretensiones tales como un supuesto derecho al aborto ${ }^{55}$. Si bien se trata de una construcción interesante, nos parece que no es aplicable en Chile. Ello debido a la naturaleza más restringida de la privacidad en el ordenamiento nacional y a la existencia de un derecho expreso a la integridad física y psíquica en nuestra CP, el cual se aplica directa y específicamente, haciendo innecesario recurrir a una interpretación tan amplia y hasta forzada de la privacidad.

\section{LIBERTAD DE CONCIENCIA}

(Artículo $19 \mathrm{~N}^{\circ} 6$ de la CP; artículo 14 de la Convención; artículo 18 de la DUDH; artículo 12 de la CADH, y artículo 18 del PIDCP)

Concebimos la libertad de conciencia no solo como la facultad de "pensar y adherir a la verdad de cualquier orden que le presente su inteligencia, y de hacerlo espontáneamente sin presiones de ninguna especie" 56 , sino también como la prerrogativa de tomar decisiones y ordenar la propia vida en base a tales convicciones.

En el tratamiento médico, el paciente puede verse enfrentado a la decisión de someterse o no a un procedimiento necesario para su salud, pero que no se condice con sus creencias. El típico ejemplo es el caso de los Testigos de Jehová que necesitan de transfusiones de sangre, cuestión que tiende a enfrentar a pacientes y médicos tratantes ${ }^{57}$.

Cuando el paciente es un niño, la cuestión se complica notablemente, toda vez que las conciencias que pueden verse violentadas son ahora dos: la del paciente y la de quienes deciden por él. Así, al margen de la opinión del médico, puede ser que el hijo desee someterse a tratamientos rechazados por los padres, o a la inversa.

Cuando los padres imponen su voluntad sobre el niño, nos hallamos frente a una infracción a la libertad de conciencia del niño que debe ser adecuadamente justificada.

\section{DERECHO A LA IGUALDAD}

(Artículo 19 No 2 de la CP; artículo 2o No 1 de la Convención; artículo 24 de la CADH; artículos $1^{\circ}$ y $7^{\circ}$ de la DUDH; artículos $3^{\circ}$ y 26 del PIDCP).

Es evidente que este valor-principio-derecho se podría ver afectado al negar a los niños la facultad de asentir o rechazar sus tratamientos médicos. En efecto, el niño sería una persona imposibilitada de decidir acerca de una materia en que los adultos gozan de gran autonomía. Se trataría, por tanto, de una discriminación por edad.

Cabe realizar dos precisiones a este respecto. La primera es que el derecho a la igualdad no implica un trato exactamente idéntico a todas las personas. Sin querer entrar en las complejidades existentes en este tópico ${ }^{58}$, es claro que se puede otorgar

\footnotetext{
55 SILVA (2006) p. 234.

56 Supranota 46.

57 E.g., Fernández (2001); Fermandois (2006) pp. 252-263; Silva (2006) pp. 96-116, y Cea (2004) pp. 119-138.

58 FANLO (2008) p. 175.
} 
tratos distintos en la medida que ello obedezca a un patrón legítimo de diferenciación. La legitimidad de aquel dependerá, a su vez, del estándar o metodología seleccionada (e.g., razonabilidad, proporcionalidad). En la terminología constitucional, ello es lo que permite, precisamente, distinguir una discriminación de una simple distinción, ya que la primera envuelve una diferenciación arbitraria, caprichosa, desproporcionada o injustificable.

La segunda precisión consiste en reconocer a la edad como factor constitucionalmente permisible de distinción en ciertos contextos. Es así como el artículo 19 número 16 de la CP lo establece a propósito de la discriminación en materia laboral, siempre y cuando goce de consagración legal. Del mismo modo, el artículo 13 de la CP restringe el derecho de sufragio y los demás derechos que otorga la ciudadanía a los mayores de 18 años, y los artículos 25, 48 y 50 establecen requisitos calificados de edad para ser elegido Presidente de la República, diputado y senador, respectivamente.

Como consecuencia de todo lo anterior, consideramos que si bien es posible afirmar que la falta de consentimiento del niño a su tratamiento médico puede constituir una vulneración a la igualdad, ello no es necesariamente así. En efecto, la distinción entre niños y adultos para estos efectos será permisible si cumple con dos requisitos copulativos: i) formalmente fundamentada en una norma jurídica de rango legal o constitucional; ii) ser proporcionada en relación a la finalidad legítima invocada.

En nuestra opinión, el primer requisito se cumple no solo en razón de las normas pertinentes del Código Civil, sino que primordialmente gracias a disposiciones contenidas en al CP y en tratados internacionales vigentes en Chile. En cuanto a la segunda exigencia, creemos que existe a lo menos una finalidad legítima en la diferenciación en comento. Aquella no otorgan una suerte de "manto de blancura" a toda intervención paterna o estatal, sino que se requiere un análisis caso a caso para determinar la efectiva y suficientemente sólida relación entre la intervención y la finalidad invocada.

El análisis de los requisitos antes enunciados integra la esencia de este trabajo, por lo que nos referiremos a ellos en extenso en la próxima sección.

\section{JUSTIFICACIÓN Y LÍMITES A LA INTERFERENCIA PATERNA EN LOS DERECHOS FUNDAMENTALES DEL NIÑO}

Hemos afirmado que el niño cuenta con una serie de derechos consagrados en nuestra CP, así como en tratados internacionales ratificados por Chile y que se encuentran vigentes. También hemos señalado como algunos de tales derechos se ven interferidos cuando se priva al niño de la facultad de decidir acerca de sus tratamientos médicos. Llama entonces profundamente la atención que a la fecha no se haya elaborado en forma sistemática la justificación y condicionamientos constitucionales para tales interferencias, dando por hecho que los padres o representantes pueden sustituir sin más la voluntad del niño en tales situaciones. A continuación propondremos esquemáticamente tales justificaciones y condicionamientos. 


\section{FUNDAMENTO}

Nuestra tesis postula como su pilar fundamental la existencia de un derecho de los niños a ser asistidos en el ejercicio de sus derechos fundamentales, el cual emana de su propia naturaleza de seres humanos que atraviesan una etapa particular de desarrollo intelectual y afectivo.

Entendemos que el carácter de derecho autónomo de esta prerrogativa de los niños puede ser resistido, toda vez que podría constituir una muestra más de lo que se ha llamado "inflación de derechos". En razón de lo anterior, existen ciertas alternativas a la naturaleza de "derecho" propiamente tal. Así, puede afirmarse que los derechos fundamentales de los niños suponen, para su plena efectividad, la asistencia de otros seres humanos para su adecuado ejercicio. Como recuerda Fanlo: "los niños no pueden ser abandonados a sus propios derechos" 59 . Bajo esta perspectiva, se podría señalar que los derechos de los niños tienen un contenido especial, o adicional, que fundamentaría la exigibilidad de ayuda o asistencia particular para hacerlos operativos. Una tercera opción consistiría en hablar derechamente de obligaciones, poniendo el acento en los deberes que emanan para la familia y, eventualmente, para el Estado, de la situación fáctica en que se encuentran los niños. En efecto, debemos recordar que en el derecho internacional se ha hablado del principio de protección especial en un sentido similar ${ }^{60}$.

Si bien nos parece que la perspectiva correcta es la primera (derecho de asistencia), creemos que cualquiera de las alternativas señaladas (contenido adicional de los derechos de los niños, obligación/deber o principio) puede fundamentarse en tres fuentes constitucionalmente aceptables:

a) La naturaleza humana. Recordemos que nuestra CP se fundamenta en un concepción iusnaturalista ${ }^{61}$, reconociendo que las realidades jurídicas más importantes arrancan en última instancia de la esencia del ser humano (artículo $5^{\circ}$ de la CP) y de la dignidad que ella supone ${ }^{62}$. En este contexto, y aunque no hubiese fundamento normativo alguno para el derecho en cuestión, es una realidad consubstancial al hombre que aquel no puede ejercer plena y libremente sus derechos mientras no alcance un adecuado grado de madurez y crecimiento ${ }^{63}$. Un recién

\footnotetext{
59 Aguilar (2008) p. 239.

$60 \mathrm{Si}$ bien estamos concientes que nuestra CP también recogió otras influencias relevantes, tales como el neoliberalismo y una concepción protegida de la democracia.

${ }^{61}$ Es difícil encontrar un concepto de dignidad en la doctrina constitucional, la que tiende a centrarse en sus consecuencias o fundamentos más que en sus contenidos (e.g., CEA (2004) pp. 170-171; SILVA (1997) pp. 30-31). Sin embargo, Aldunate (2008) p. 99 señala que es "el valor de la potencia de desarrollo humano individual hacia la realización de autodeterminación racional y libre de cada persona, presente en las relaciones humanas". Ahora bien, existe discrepancia acerca de si para nuestra Constitución la dignidad humana es la fuente de los derechos fundamentales (contrastar AldunATE (2008) p. 100 y CEA (2004) pp. 170-171). A nivel comparado, las diversas relaciones entre derechos fundamentales y dignidad humana desde la perspectiva de la interpretación judicial ha sido magistralmente abordada en MCCRUDDEN (2008).

62 PAVEZ (2004) p. 61.

63 Reconocemos que esta idea puede no ser completamente pacífica, particularmente si ella exige formular la aseveración general de que el derecho a la vida incluye "aquello que mínimamente uno necesita para que la vida continúe” FigUeroA (2008) p. 273.
} 
nacido tiene derecho a la vida, pero su ejercicio requiere de la asistencia directa y constante de otros seres humanos. A nuestro juicio, ese infante tiene un derecho a dicha asistencia, no porque lo establezca la CP, sino porque lo decretan la mismísima naturaleza humana y su dignidad de persona. De lo contrario, simplemente moriría, resultado inaceptable y absurdo si efectivamente le reconocemos el derecho en cuestión ${ }^{64}$. Lo anterior se vincula directamente al principio de realidad o efectividad real de los derechos fundamentales, en virtud del cual, aquellos no son solo declaraciones simbólicas, sino por el contrario, exigencias justiciables que deben gozar de vigencia concreta y palpable en la realidad cotidiana. Sin este derecho a la asistencia, los niños, particularmente los más pequeños, no tendrían oportunidad alguna de ejercer sus derechos fundamentales.

b) La Familia. Una segunda fuente constitucional de este derecho a la asistencia es el reconocimiento de la familia como el núcleo fundamental de la sociedad (artículo $1^{\circ}$ inciso $2^{\circ}$ ), así como el deber estatal de dar protección a la familia y propender a su fortalecimiento (artículo $1^{\circ}$ inciso $5^{\circ}$ ). Siendo la familia una sociedad natural, reconocida y no creada por la CP, dicho reconocimiento no solo alcanza al hecho de su existencia, sino también a sus características y fines esenciales. Dentro de tales fines se encuentran la protección de la prole así como el desarrollo de las potencialidades de sus miembros. De esta forma, la familia naturalmente da respuesta y cumplimiento al derecho de asistencia de los niños de que estamos hablando. Aquella es la primera y preferentemente llamada a tal rol, y de ahí emana en última instancia la potestad paterna para sustituir la voluntad de los hijos (niños) frente al tratamiento médico. En realidad, visto desde esta perspectiva, se trata de un deber más que de un derecho ${ }^{65}$, el cual se encuentra también reconocido en diversos tratados internacionales, cuestión que trataremos a continuación.

c) El Derecho Internacional. La tercera fuente que podemos identificar son los tratados internacionales sobre derechos de los niños. Todos estos instrumentos, constitucionalmente reconocidos en el artículo $5^{\circ}$ de la CP, parten del supuesto básico de que los niños requieren no solo la protección especial de los adultos en razón de su inmadurez ${ }^{66}$, sino también su ayuda en el ejercicio de sus derechos. Esa es una de sus razones de ser más profundas, ya que junto con recordarnos los derechos de los niños, imponen al Estado, la sociedad y los padres, un conjunto de obligaciones que permitan a los niños gozar empíricamente de los mismos.

Así, por ejemplo la DDN señala en su Preámbulo lo siguiente "Considerando que el niño, por su falta de madurez física y mental, necesita protección y cuidado especiales, incluso la debida protección legal, tanto antes como después del nacimiento", idea recogida en forma expresa por el Preámbulo de la Convención y similar a lo preceptuado

\footnotetext{
${ }^{64}$ Cillero (1999) p. 6.

65 FANLO (2008) p. 161.

66 Cillero (2008) p. 131.
} 
en el artículo 25 de la DUDH. La misma DDN agrega en su Principio 2 que "El niño gozará de una protección especial y dispondrá de oportunidades y servicios, dispensado todo ello por la ley y por otros medios, para que pueda desarrollarse física, mental, moral, espiritual y socialmente en forma saludable y normal". Por su parte, la CADH dispone, en su artículo 19, que "Todo niño tiene derecho a las medidas de protección que su condición de menor requieren por parte de su familia, de la sociedad y del Estado", y la Convención reafirma en su artículo $5^{\circ}$ el derecho y deber de la familia de impartirle "dirección y orientación apropiadas para el que niño ejerza los derechos reconocidos en la presente Convención”. En la misma línea se insertan el artículo 24 del PIDCP y el artículo 10 del Pacto Internacional de Derechos Económicos, Sociales y Culturales ("PIDESC").

Más aún, estos mismos tratados internacionales reconocen el rol fundamental que juega la familia en estas materias. Es así como "la Convención es profundamente respetuosa de la relación niño-familia (...) limitando la intervención del Estado a una última instancia que supone que han fallado los esfuerzos de la familia y los programas sociales generales"67 68. En efecto, el Preámbulo de la Convención señala lo siguiente:

"Convencidos de que la familia, como grupo fundamental de la sociedad y medio natural para el crecimiento y el bienestar de todos sus miembros, y en particular de los niños, debe recibir la protección y asistencia necesarias para poder asumir plenamente sus responsabilidades dentro de la comunidad"

A mayor abundamiento, su artículo $5^{\circ}$ establece que:

"Los Estados Partes respetarán las responsabilidades, los derechos y los deberes de los padres o, en su caso, de los miembros de la familia ampliada o de la comunidad (...)".

Por su parte, el artículo 18 de la Convención señala expresamente que:

"Incumbirá a los padres (...) la responsabilidad primordial de la crianza y el desarrollo del niño (...) los Estados Partes prestarán la asistencia apropiada a los padres y a los representantes legales para el desempeño de sus funciones".

Otras disposiciones relevantes ya mencionadas son el artículo 17 de la CADH, el artículo $16 \mathrm{~N}^{\circ} 3$ de la DUDH, el artículo 23 del PIDCP y el artículo 10 del PIDESC.

En definitiva, observamos cómo los tratados internacionales, en sus articulados o en sus preámbulos (que aunque no estrictamente vinculantes, constituyen marcos interpretativos de relevancia), reconocen que la vigencia efectiva de los derechos del niño requiere de la acción y asistencia de otros, y que los primeros llamados a

67 Álvarez (1994) pp. 95 y ss.

${ }^{68}$ Cillero (1999) p. 3. 
tal labor son la familia o los padres. A su vez, el Estado ostenta un rol subsidiario, debiendo desarrollar las políticas de fomento y protección necesarias, e interviniendo directamente en la relación familiar solo en última instancia ${ }^{69}$.

Quisiéramos cerrar este punto acerca del fundamento de la intervención paterna con dos reflexiones adicionales. La primera es que, al menos respecto de ciertos tratamientos médicos, como aquellos vinculados a la salud sexual, es posible intentar justificar el derecho de los padres a interferir en el ejercicio de los derechos fundamentales de los hijos, basados en el derecho preferente y en el deber de educarlos (artículo $19 \mathrm{~N}^{\circ} 10$ de la CP $)^{70}$. Sin embargo, creemos que ello es errado. En efecto, si bien el proceso de educación es particularmente amplio, especialmente en su dimensión informal, resulta claro para el derecho constitucional que aquel apunta a la transmisión y desarrollo de valores, conocimiento y destrezas ${ }^{71}$. Aunque los padres pueden, con ocasión de un tratamiento médico, ilustrar a sus hijos acerca de ciertos valores, virtudes o sapiencia, ello no constituye el objeto en sí de la intervención paterna, sino solo un elemento marginal y accidental. Más aún, cualquier circunstancia de la vida puede ser utilizada por los padres para educar a sus hijos, lo que no necesariamente somete tales circunstancias al ámbito protegido del derecho en comento. En consecuencia, no es posible utilizar el derecho a educar como fundamento general de la facultad de los padres de decidir por sus hijos en las materias en estudio.

La segunda reflexión consiste en recordar los artículos 222 y 224 del Código Civil. Aquellos disponen lo siguiente:

Art. 222 inciso $2^{\circ}$

"La preocupación fundamental de los padres es el interés superior del hijo, para lo cual procurarán su mayor realización espiritual y material posible, y lo guiarán en el ejercicio de los derechos esenciales que emanan de la naturaleza humana de modo conforme a la evolución de sus facultades" (el subrayado es nuestro).

Art. 224 inciso $1^{\circ}$

Toca de consuno a los padres, o al padre o madre sobreviviente, el cuidado personal de la crianza y educación de sus hijos.

Si bien el rango legal de estas normas nos impide adoptarlas como fundamento constitucional de las interferencias de los padres en el ejercicio de los derechos funda-

\footnotetext{
${ }^{69} \mathrm{Tal}$ argumentación puede encontrarse en el requerimiento en contra de la "píldora del día después", si bien no fue exitosa en esa ocasión TRibunal ConstiTuCIONAL (2008) rol o 740.

70 Tribunal Constitucional (2008) rol No 914, considerando Decimocuarto y siguientes, y artículo $2^{\circ}$ de la Ley No 18.962 Orgánica Constitucional de Enseñanza, y CEA (2004) pp. 323-325.

${ }^{71}$ Como dice Brugueras, hoy es claro que los hijos no son propiedad de los padres. BRUGUeras (2004) p. 25 .
} 
mentales de sus hijos, no cabe duda que aquellos contribuyen a demostrar el espíritu de nuestro ordenamiento jurídico en la materia, y cómo el legislador intenta reflejar y desarrollar las disposiciones constitucionales. Ello particularmente en razón de la fidelidad con que tales preceptos recogen las ideas antes planteadas. Más aún, según lo señalado más arriba, nosotros opinamos que estas normas legales arrancan directamente de la naturaleza misma de la familia, la cual a su vez goza de reconocimiento constitucional directo (artículo $1^{\circ}$ de la CP).

\section{CONDICIONAMIENTOS O LÍMITES A LA INTERVENCIÓN PATERNA}

La intervención de los padres en materia de tratamientos médicos, si bien constitucionalmente legítima, no puede concebirse como una carta blanca para su libre arbitrio $^{72}$, ni tampoco como un asunto exclusivamente privado o familiar ${ }^{73}$. Se trata de un derecho-deber de cuidado que jamás puede utilizarse en perjuicio del niño ${ }^{74}$, que obedece a finalidades específicas y que constituye en sí mismo una gran excepción, toda vez que se trata de una suerte de representación en el ejercicio de derechos que son personalísimos, y por tanto indelegables.

Enunciaremos a continuación las principales condicionantes o limitantes de las facultades paternas en estas materias.

\section{a) El Principio Evolutivo o de Desarrollo Progresivo}

En la sección precedente identificamos un derecho de los niños a ser asistidos en el ejercicio de sus derechos fundamentales. Ahora bien, al hablar de "asistencia" nos referimos a la ayuda y colaboración temporal que se provee a quien no puede ejercer esos derechos por sí mismo, cuestión que en ocasiones puede suponer derechamente la sustitución de la voluntad del niño ${ }^{75}$. De esta forma, la intervención de los padres solo se justifica en la medida que sus hijos no sean capaces de ejercer sus derechos plenamente por sí solos, normalmente en razón de su falta de madurez ${ }^{76}$.

En este contexto, resulta fundamental reconocer el principio evolutivo o de desarrollo progresivo del niño. En efecto, los niños no se convierten en adultos maduros de

\footnotetext{
72 GARCía (2001) p. 32. En otro contexto, RiVAS Y SERNA (2001) p. 291.

73 VÁSQUEZ (2002) p. 54.

${ }^{74}$ Como señala Freeman "estaríamos fallando en reconocer la integridad de un niño si le permitiéramos elegir una acción, como consumir heroína o no acudir a la escuela, que pudiera dañar seria y sistemáticamente la consecución subsecuente de la plena personalidad y el desarrollo”. FreEMAN (2006) p. 272.

75 Algunos prefieren hablar del impedimento de acciones irracionales, entendiendo por acción irracional aquella "que socavaría futuras opciones de vida y dañaría intereses de modo irreversible", y no el simple y educativo error FREEMAN (2006) p. 272. Otros se refieren a una incapacidad manifiesta para alcanzar los propios fines con eficacia y sin afectar sus intereses COUSO (2006) p. 152.

76 El derecho así lo entiende. En efecto, ya a los 14 años un niño puede ser penalmente responsable (artículo $10 \mathrm{~N}^{\circ} 2$ del Código Penal, en relación al artículo $3^{\circ}$ de la Ley No 20.084 que "Establece un Sistema de Responsabilidad de los Adolescentes por Infracciones a la Ley Penal"), y administrar su peculio profesional (artículo 251, con la excepción del artículo 254 del Código Civil). Similarmente, los mayores de 16 años pueden contraer matrimonio, si bien sujetos a autorización (Libro I, Título IV del Código Civil).
} 
un día para otro por el solo hecho de alcanzar los 18 años ${ }^{77}$. Del mismo modo, durante la minoría de edad se puede observar un continuo de etapas de desarrollo y de madurez que no es posible asociar con total precisión a una determinada edad. El niño es por definición un desarrollo y una maduración constante. Se trata de un proceso que se manifiesta con características particulares en cada caso.

En la medida que el niño va madurando, la asistencia de los padres en el ejercicio de sus derechos es cada vez menos necesaria, hasta llegar al punto en que se hace del todo redundante ${ }^{78}$. En tales casos, la legitimidad constitucional de la intervención paterna ha dejado de existir, por lo que los padres deben abstenerse de ejercerla.

De este modo, nos parece que el principio en estudio nos obliga a asumir como un hecho fáctico que los niños sí pueden ser capaces de adoptar decisiones racionales en relación a sus tratamientos médicos. Es así como se ha sostenido que "la evidencia parece demostrar que los niños tienen la capacidad cognitiva para tomar decisiones racionales a una edad menor de la que establece la ley (...) En el área del desarrollo cognitivo, casi todos los científicos sugieren que los niños, desde los 14 años en adelante, poseen un nivel cognitivo e intelectual similar al de los adultos, en lo relativo al discernimiento. Incluso la mayoría de los científicos están de acuerdo con que los niños alcanzan este nivel a la edad de 12 años"79 ${ }^{80}$. Del mismo modo, los niños de hasta 7 años manifiestan una capacidad considerable de razonamiento lógico ${ }^{81}$. En conclusión, debemos asumir que la situación de los niños en la materia en estudio responde a convenciones o imaginarios sociales que están quedando obsoletos.

A nuestro juicio, los principales fundamentos constitucionales de este principio evolutivo son los siguientes:

i) La naturaleza humana y de las relaciones familiares: nuevamente nos encontramos frente a una realidad que precede al derecho y que este se limita a reconocer. Es un hecho innegable y evidente que los niños van desarrollando progresivamente sus facultades intelectuales, volitivas y afectivas. También es una realidad indiscutible que la intervención de los padres en la vida de sus hijos va decreciendo en la medida que estos crecen y se desarrollan, independientemente de que la ley les otorgue prácticamente los mismos derechos y facultades sobre sus hijos desde que estos nacen y hasta los 18 años. Tales realidades naturales están reconocidas en la Constitución en sus artículos $1^{\circ}$ y $5^{\circ}$. Adicionalmente, tal y como comentábamos precedentemente, el reconocimiento constitucional de la familia (artículo $1^{\circ}$ inciso $2^{\circ}$ ) y los deberes del Estado para con ella (artículo $1^{\circ}$ inciso $5^{\circ}$ ), implican

\footnotetext{
77 Es así como los derechos de los niños buscan, precisamente, favorecer el desarrollo de su personalidad y su integración en las mejores condiciones posible a la vida adulta, JiMÉNEZ (2001) p. 5.

78 MASON (2004) p. 122.

79 Según RUEDA (2008) pp. 10-12, la presunción sobre los 14 años debe ser la capacidad para decidir. Bajo los 12 años la regla debiera ser la inversa. Entre los 12 años y los 14 años sería imposible formular una regla general.

${ }^{80}$ MASON (2004) p. 123.

81 Obviamente en la medida que aquellos son fieles a la naturaleza misma de la familia, lo que excluiría, por ejemplo, prácticas de violencia familiar.
} 
identificarla como un todo: no solo su existencia, sino también sus características, finalidades y los procesos naturales que se dan en su interior ${ }^{82}$.

ii) El artículo $5^{\circ}$ de la Convención, el cual dispone lo siguiente:

"Los Estados Partes respetarán las responsabilidades, los derechos y los deberes de los padres $o$, en su caso, de los miembros de la familia ampliada o de la comunidad, según establezca la costumbre local, de los tutores $u$ otras personas encargadas legalmente del niño de impartirle, en consonancia con la evolución de su facultades, dirección y orientación apropiadas para que el niño ejerza los derechos reconocidos en la presente Convención".

El texto de la Convención es claro: el derecho de intervención de los padres y la asistencia que deben brindar a sus hijos no es un derecho que se mantiene y se ejerce en forma estática durante la minoría de edad de estos. Por el contrario, aquel debe ir variando en formas y en intensidad para ir ajustándose al desarrollo del niño ${ }^{83}$.

Existe un tercer fundamento normativo, pero no de carácter constitucional, cual es el ya transcrito artículo 222 inciso $2^{\circ}$ del CC, el cual dispone que los padres guiarán a sus hijos en el ejercicio de sus derechos "de modo conforme a la evolución de sus facultades". En la misma línea se inserta el artículo 242 del CC, el cual ordena al juez tenga en consideración las opiniones de los hijos "en función de su edad y madurez", cuestión que obliga a un análisis concreto y contextualizado de la situación y capacidades del niño ${ }^{84}$. En todo caso, nos remitimos a lo ya señalado en cuanto al valor relativo como argumento constitucional de estas disposiciones legales.

Finalmente, destacamos que, en nuestra opinión, este principio evolutivo o de desarrollo progresivo no admite criterios de edad rígidamente aplicados ${ }^{85}$, sino que obliga siempre a un análisis caso a caso. Ello no significa, sin embargo, que el legislador no pueda establecer ciertos límites objetivos de edad. En efecto, aquellos podrían ser de gran utilidad siempre un cuando permitan su aplicación flexible, insertándose así dentro de las alternativas que el legislador puede adoptar legítimamente dentro de nuestro marco constitucional.

Es así como a diferencia de la Convención, para la cual todos los menores de 18 son simplemente niños (artículo $1^{\circ}$ ), diversos autores y varios países latinoamericanos han reconocido al menos una distinción relevante entre impúberes y menores adultos, o entre niños y adolescentes ${ }^{86}$. La principal consecuencia de esta clasificación para nuestro

\footnotetext{
82 ÁlVArez (1994) pp. 95 y ss.

83 Correa y VALDivia (2001) p. 70.

${ }^{84}$ LATHROP (2004). Ejemplos de literatura general referida a la "capacidad natural" o "menor maduro" son BerRo (2001) p. 46.; SANCHO (2004) p. 20.; MAGLIO (2001) p. 38, y BóRQUEZ et al. (2004) p. 1244.

85 Correa y Valdivia (2001) p. 53; Cillero (1999) p. 6.

${ }^{86}$ Es así como el proyecto de ley que "Regula los derechos y deberes que tienen las personas en relación con acciones vinculadas a su atención en salud" (boletín No 4398-11), distingue entre los menores y mayores de 14 años. En el caso de los primeros, sus padres o representantes legales son los llamados a decidir respecto a sus tratamientos médicos (artículo 16). Quienes ya han cumplido 14 años deben ser directamente informados por el médico tratante. Los padres o representantes legales también deben ser instruidos, a menos que el menor se oponga, en cuyo caso el facultativo puede guardar silencio "si estima que la situación del menor no implica grave riesgo para su salud o su vida" (art. 8). En caso de duda, el médico debe consultar al comité de ética respectivo.
} 
tópico es que se parte de la presunción de que los niños o impúberes no tienen suficiente conciencia y discernimiento, por lo tanto bastaría informarles en términos muy genéricos y simples respecto del tratamiento médico que se les va a aplicar, pero dejando siempre a los padres la decisión final. A los menores adultos o adolescentes, en cambio, se les reconocería mayor capacidad de decisión en tales materias, pudiendo decidir sobre sus tratamientos médicos, gozando de confidencialidad en su relación con el médico tratante, etc., salvo en circunstancias de especial gravedad (e.g., vida en peligro) o anormalidad (e.g., notoria inmadurez, irracionalidad en la decisión) ${ }^{87}$.

No obstante las ventajas de la distinción anterior, fundamentalmente en términos de certeza jurídica, insistimos que aquella no puede aplicarse rígidamente, a la usanza del Derecho Civil. Ello por cuanto en materia de derechos fundamentales el principio de realidad se impone, y no resulta permisible que una persona perfectamente capaz de ejercer por sí misma sus derechos fundamentales se vea privada hacerlo en razón del mal diseño de una excepción a dicha regla. En consecuencia, y utilizando la jerga probatoria tradicional, diríamos que los límites de edad deben considerarse, a lo sumo, como presunciones simplemente legales, las que si bien invierten la carga de la prueba, permiten ser desvirtuadas cuando las circunstancias particulares del caso así lo exigen.

A mayor abundamiento, establecer criterios de edad lleva aparejado un gran desafío, cual es guardar la debida armonía dentro del sistema jurídico. En efecto, si bien los seres humanos poseemos diversas dimensiones y no maduramos en forma simultánea en todas ellas, no resulta aceptable que un ordenamiento jurídico disocie inorgánica y asistemáticamente las distintas "madureces" y capacidades de asumir responsabilidades. Nos referimos, entre otras, a materias tales como la responsabilidad penal; la responsabilidad civil; las obligaciones de familia; la facultad de testar; la capacidad para reconocer hijos; la capacidad laboral; facultades patrimoniales; capacidad posesoria; capacidad de comparecencia en juicio; derechos ciudadanos y en particular el derecho de sufragio; entre otros. No estamos sosteniendo que todos estos derechos, capacidades y obligaciones deban asumirse en plenitud a la misma edad. Sin embargo, si se van a establecer diferencias, aquellas deben responder a criterios generales del ordenamiento jurídico como un todo, de forma de garantizar la armonía adecuada. En otras palabras, lo que no es aceptable es que cada rama o subrama del derecho establezca libremente los límites de edad que estime conveniente. Por el contrario, todas deberían partir de un conjunto de criterios comunes de forma que cada límite de edad que se formule sea la aplicación coherente de dichos criterios generales a la materia específica de que se $\operatorname{trata}^{88}$.

\footnotetext{
${ }^{87}$ E.g., artículos 262, 264, 723, 1005 No 2, 2319 del Código Civil; el artículo 13 del Código del Trabajo; el artículo 10 No 2 del Código Penal, y el artículo 16 inciso $3^{\circ}$ de la Ley No 19.968 que crea los Tribunales de Familia. Véanse también VÁsQUeZ (2002) p. 55; CORREA Y VALDIVIA (2001) pp. 68-70; PAVEZ (2004) pp. 64-66.

${ }^{88}$ Carmen Domínguez afirma que el término fue mal traducido: "la fórmula inglesa empleada por el art. 3 de la Convención de los Derechos del Niño es "the best interest of the child" cuya traducción correcta sería "el mejor interés del niño" y no el interés superior del niño". DomÍnguez (2001) p. 19.
} 


\section{b) La finalidad}

Uno de los criterios primordiales para determinar la legitimidad constitucional de la intervención paterna en el ejercicio de los derechos fundamentales de sus hijos, es su finalidad. Se hace entonces necesario: i) identificar la finalidad concreta del acto de intervención paterna; ii) verificar que dicha finalidad sea constitucionalmente aceptable, y iii) establecer una relación directa entre el medio elegido y la finalidad perseguida.

El tercer elemento lo analizaremos con mayor detalle en la sección siguiente. Por lo tanto, dedicaremos el resto de este apartado al estudio de la finalidad de la intervención paterna y su constitucionalidad.

A nivel internacional y de derecho comparado, se ha ido abriendo paso el interés superior del niño como finalidad rectora, no solo de las asistencias o interferencias con los derechos del niño, sino como criterio de decisión final y universal en todo lo que diga relación con ellos.

A nivel normativo, este principio aparece expresa y repetidamente consagrado tanto en la DDN (principios No s 2 y 7) como en la Convención (artículos No s 3, 9, $18,20,21,37$ y 40$)^{89}$, al punto de constituir uno de sus principios transversales. Su antecedente internacional inmediato es la Declaración de Viena, cuyo Principio 7 inciso 2 dispone que:

"El interés superior del niño debe ser el principio rector de quienes tienen la responsabilidad de su educación y orientación; dicha responsabilidad incumbe, en primer término, a sus padres".

Sin embargo, la fuerza vinculante de este principio reconoce otras raíces. En efecto, su abundante presencia en derecho comparado ${ }^{90}$ ha llevado a afirmar que aquel constituiría un principio general de derecho bajo los parámetros establecidos por el artículo 38 letra c) del Estatuto de la Corte Internacional de Justicia ${ }^{11}$. Es así como expresiones tales como welfare of the child, best interest of the child, l'intérêt supérieur de l'enfant, entre otras, demostrarían su extendida influencia en los sistemas jurídicos de diversos países. Otros, partiendo de esta misma base, afirman que se trataría de una norma de derecho internacional consuetudinario que solo habría sido positivizada por la Declaración y la Convención ${ }^{92}$, fenómeno que ayudaría a explicar el alto grado de adhesión de la Convención ${ }^{93}$.

También debemos considerar que el interés superior del niño es un concepto que ya goza de recepción en el derecho interno ${ }^{94}$, en cuanto "principio fundamental e inspirador de nuestro ordenamiento jurídico, de relevancia transversal en la legislación de

\footnotetext{
${ }^{89}$ Cillero (2008) p. 131.

${ }^{90}$ Aguilar (2008) p. 226.

91 BAEZA (2001) pp. 357 y ss., y en cierto sentido AGUILAR (2008) pp. 227 y 228.

92 Todos los miembros de la ONU lo han suscrito, con la excepción de Estados Unidos y Somalia UNICEF (2006).

93 Si bien con algunos altibajos y parcialidades. AgUILAR (2008) p. 231.

${ }^{94}$ Corte Suprema (2008) rol No 6419-2008, considerando Noveno.
} 
familia y de menores"95. En efecto, adicionalmente a su incorporación vía ratificación de la Convención en virtud del artículo $5^{\circ}$ de la $\mathrm{CP}^{96}$, existen ciertos cuerpos legales que lo han recogido expresamente. Es así como el Código Civil lo consagra en el ya varias veces mencionado artículo $222^{97}$, y en diversas ocasiones utiliza el concepto similar de "interés del hijo" (artículos 225; 242; 244; 245; 268 y 272). Del mismo modo, la Ley $\mathrm{N}^{\circ}$ 19.620 que Dicta Normas Sobre Adopción de Menores, se refiere expresamente al interés superior del menor (artículos 24 y 30), siendo para ella un concepto rector ${ }^{98}$. También habla del interés superior del adoptado (artículos $1^{\circ}$ y 22); del interés superior del menor adulto (artículo 30), y del interés del menor (artículo 12 № 3). Otro tanto se constata en la Ley $N^{\circ}$ 19.947, que Establece una Nueva Ley de Matrimonio Civil, la que consagra tanto el interés superior del niño (artículo 85) como también el interés superior de los hijos (artículos 3o; 27, y 55). A su vez, la Ley No 19.968, que Crea los Tribunales de Familia, afirma en su artículo 16 que el interés superior del niño, niña o adolescente es un principio rector que el juez "debe tener siempre como consideración principal en la resolución del asunto sometido a su conocimiento", volviendo a recoger tal concepto en su artículo 19. Del mismo modo, la Ley No 20.084, que Establece un Sistema de Responsabilidad de los Adolescentes por Infracciones a la Ley Penal, articula su aplicación en base al "Interés superior del adolescente" (artículo 20). A mayor abundamiento, el concepto en cuestión estaría siendo utilizado y reconocido por la jurisprudencia99.

Ahora bien, la determinación de qué se debe entender por el interés superior del niño se presenta como una dificultad relevante. De la revisión bibliográfica señalada, queda la impresión de que ni los autores ni la jurisprudencia han elaborado una doctrina común sobre el punto ${ }^{100}$. En realidad, se ha escrito mucho más acerca de las funciones del término, i.e., para qué podría servir, más que sobre su contenido propiamente tal. Es así como se ha señalado que se trata de un "instrumento jurídico que tiende a asegurar el bienestar del niño en el plan físico, psíquico y social. Funda una obligación de las instancias y organizaciones públicas o privadas a examinar si este criterio está realizado en el momento en el que una decisión debe ser tomada con respecto a un niño y que representa una garantía para el niño de que su interés a largo plazo será tenido en cuenta. Debe servir de unidad de medida cuando varios intereses entran en convergencia" ${ }^{101}$. También se ha señalado que se trata de un principio general de derecho que debe

\footnotetext{
95 BAEZA (2001) p. 359.

${ }^{96}$ Este precepto fue agregado por la Ley $\mathrm{N}^{\circ}$ 19.585, que Modifica el Código Civil y Otros Cuerpos Legales en Materia de Filiación, la cual habría consagrado inequívocamente la supremacía del interés superior del niño Correa y VALDivia (2001) p. 66.

97 BAEZA (2001) p. 360

98 Corte Suprema (2006) rol No 6553-2006; CorTe Suprema (2008) rol No 6419-2008; CORTE DE Apelaciones de SANTiago (2004) rol No 4105-2004; BAEZA (2001) p. 361 y Cillero (2008) p. 126.

${ }^{99} \mathrm{La}$ dispersión y variedad es sorprendente. Incluso se ha afirmado su naturaleza de deber moral juridizado BAEZA (2001) p. 357, o de "interés social amparado por el derecho" CORTE SUPREMA (2006) rol No 6553-2006, considerando Sexto.

100 ZERMATTEN (2003) p. 15.

101 LATHROP (2004) p. 221. García (2001) pp. 33 y 34, se enfoca en el mayor interés de los incapaces en general y no de los menores en particular.
} 
ser concretado por los legisladores y jueces, y que por tanto es esencialmente dinámico y contextualizado ${ }^{102}$. Aquel comprendería "una serie de criterios que apuntan a amparar el pleno desarrollo y la total autorrealización del niño en su entorno y a proteger y garantizar la valiosa contribución que el niño debe hacer a la sociedad"103.

Complementando lo anterior, la Corte Interamericana de Derechos Humanos ha señalado que "La prevalencia del interés superior del niño debe ser entendida como la necesidad de satisfacción de todos los derechos de los menores, que obliga al Estado e irradia efectos en la interpretación de todos los demás derechos de la Convención cuando el caso se refiera a menores de edad"104. También ha fallado que se funda "en la necesidad de propiciar el desarrollo de estos [los niños], con pleno aprovechamiento de sus potencialidades" 105 .

En definitiva, entendemos que el interés superior del niño serviría para fundar ciertas obligaciones; para solucionar conflictos de derechos ${ }^{106}$ o intereses ${ }^{107}$; como garantía para dar efectividad a los derechos de los niños ${ }^{108}$; como orientador de políticas públicas y normas jurídicas ${ }^{109}$; como principio interpretativo ${ }^{110}$, particularmente de tratados que contengan derechos fundamentales aplicables a los niños; como criterio general de decisión ${ }^{111}$; como elemento de control de la debida protección de los niños ${ }^{112}$, e incluso como solucionador de vacíos legales en la materia ${ }^{113}$. En cuanto a su contenido, la diversidad de pareceres es notoria, afirmándose que se vincula o comprende el beneficio a largo plazo del niño ${ }^{114}$; los "bienes necesarios para el desarrollo integral y la protección de la persona del menor de edad y, en general, de sus derechos, que buscan su mayor bienestar"115; lo que "hubiese decidido una persona razonable en esas circunstancias"116; el reconocimiento de las capacidades del niño de expresar sus preferencias y opiniones; la consideración de "las características particulares de la situación en la que se halla el niño" así como su grado de desarrollo ${ }^{117}$; la "necesidad de propiciar el

\footnotetext{
102 Aguilar (2008) p. 238.

103 Corte Interamericana de Derechos Humanos (2005) Yean y Bosico vs. República Dominicana, punto 134 .

104 Buscar fuente directa en AgUiLar, pp. 242-243.

105 Cillero (2008) p. 137; Gómez de la Torre (2000) p. 23, y Fernández (2008) Sección III; "Corte Suprema (2006) rol No 6553-2005, considerando Noveno.

106 Couso (2006) p. 147.

107 Cillero (2008) p. 134; Gómez de la Torre (2000) p. 23, y Corte de Apelaciones de Santiago (2004) rol No 4105-2004, considerando Quinto.

108 Gómez de la TOrre (2000) p. 23; Cillero (2008) p. 138 y ZERMATTen (2003) pp. 16 y ss.

109 Gómez de la Torre (2000) p. 23; Cillero (1999) p. 8.; PAVez (2004) p 114; Zermatten (2003)

p. 11; Cillero (2008) pp. 128 y 137, y Corte Suprema (2006) rol No 6553-2005, considerando Sexto.

110 ZERMATTEN (2003) p. 11.

111 ZERMATTEN (2003) p. 11.

112 Cillero (2008) p. 138.

113 ZERMATTEN (2003) p. 15.

114 BAEZA (2001) p. 356.

115 GARCÍA (2001) p. 34.

116 Aguilar (2008) p. 245.

117 Corte Interamericana de Derechos Humanos (2003) Bulacio vs. Argentina, punto 134.
} 
desarrollo de estos [los niños] con pleno aprovechamiento de sus potencialidades"118; "la plena satisfacción" de los derechos del niño ${ }^{119}$; el "instrumento jurídico concebido por la Convención” para alcanzar el bienestar del niño ${ }^{120}$, entre otros.

Frente a esta diversidad conceptual, evidenciadora de confusión e indeterminación, pero también de flexibilidad ${ }^{121}$, parece evidente concluir que se trata de un concepto jurídico indeterminado, tal y como lo ha reconocido nuestra jurisprudencia ${ }^{122}$. En consecuencia, el interés superior del niño debe ser precisado por el juez, con o sin la guía del legislador, de acuerdo a las circunstancias particulares del caso concreto. Idealmente, la jurisprudencia debe ir identificando estándares o criterios que sirvan para evaluar cada situación particular. Destaca a este respecto la sentencia de la Corte de Apelaciones de Santiago, rol No 4105-2004, la cual singularizó en su considerando Sexto los siguientes factores a considerar: "a) las necesidades materiales, educativas y emocionales del menor y la probabilidad de que sean cubiertas por quien pretende la tuición; b) la capacidad y condiciones de la solicitante para asumir la tuición; c) el efecto probable de cualquier cambio en la situación en la vida actual del menor; y d) si existiere algún daño sufrido o riesgo de sufrirlo por consecuencia de la tuición”. Si bien resulta evidente que se trata de criterios vinculados a un tópico específico -la tuiciónpodemos observar cómo el juez atiende a ciertos factores generalizables: el bienestar físico y psíquico del niño (a, c y d) y las calidades de quienes se relacionan con él (b). Otro criterio utilizado por la jurisprudencia nacional ha sido la consideración de las probables situaciones futuras como parte del bienestar general del niño, descartando de ese modo la sola atención a sus circunstancias actuales ${ }^{123}$.

Ahora bien, dentro de la confusión o indeterminación conceptual enunciada, creemos que la labor de efectiva incorporación y determinación del interés superior del niño exige al juez poner especial atención al concepto de Bien Común. En efecto, sabemos que nuestra definición constitucional de Bien Común fue extensamente debatida en la Comisión de Estudios de la Nueva Constitución, toda vez que no se trata de un concepto neutro, sino que impregnado de un contenido filosófico-dogmático determinado ${ }^{124}$. Es ese

\footnotetext{
118 Cillero (2008) p. 134; COUSO (2006) p. 148, y LinACERO (2001) pp. 60 y ss.

119 ZERMATTEN (2003) p. 10.

120 ZERMATTEN (2003) p. 13.

121 CORTE SUPREMA (2008) rol No 6419-2008, considerando Noveno y CORTE DE APELACIONES DE SANTIAGO (2004) rol No 4105-2004, considerando Quinto.

122 Corte Suprema (2006) rol No 6553-2005, considerando Noveno.

123 La noción de Bien Común fue intensamente debatida en la Comisión de Estudios para la Nueva Constitución, imponiéndose la visión de incluir una definición en el texto constitucional que diera cuenta de la necesidad de armonizar el bien de la colectividad con el bien particular de cada individuo. Particular interés presenta la intervención del comisionado Guzmán en la sesión 45. El origen doctrinal de este concepto debe buscarse en Gaudium et Spes, donde se define bien común como "el conjunto de condiciones de la vida social, que hacen posible a las asociaciones y a cada uno de sus miembros, el logro más pleno y más fácil de la propia perfección”. CONCILIO VATICANO II (1965).

${ }^{124}$ En la historia fidedigna de la Ley No 19.585, la cual introdujo la redacción actual del artículo 222 del Código Civil, aparece expresamente que el interés superior del niño "a que refiere la Convención [de los Derechos del Niño] se enlaza con la aspiración constitucional de procurar la mayor realización espiritual y material posible de cada persona”. HISTORIA DE LA LEY 19.585 (1998) p. 898.
} 
mismo contenido el que nos permite deducir obligaciones y requerimientos concretos que emanan del Bien Común, convirtiéndolo en un concepto rector de real importancia y aplicación en nuestro sistema. Adicionalmente, sabemos que el Bien Común es una noción que reúne armónicamente las diversas finalidades impuestas al Estado, por lo que toda obligación o deber estatal debe ser reconducible, en última instancia, al Bien Común. Finalmente, debemos recordar que la propia CP establece que aquel no constituye una creación estatal, ya que el Estado solo contribuye a crear las condiciones necesarias para alcanzarlo. Más aún, en tal labor debe también participar la sociedad, y en primerísima instancia, las propias personas.

En este contexto, recordemos que nuestra CP establece lo siguiente en su artículo $1^{\circ}$ inciso $4^{\circ}$ :

"El Estado está al servicio de la persona humana y su finalidad es promover el bien común, para lo cual debe contribuir a crear las condiciones sociales que permitan a todos y a cada uno de los integrantes de la comunidad nacional su mayor realización espiritual y material posible, con pleno respecto a los derechos y garantías que esta Constitución establece"

Dicho lo anterior, resulta evidente que el interés superior del niño, y más precisamente, su consecución y promoción por parte de los diferentes órganos estatales -incluyendo el juez-, se enmarcan necesariamente dentro de la creación de las condiciones que permitan el mayor bienestar material y espiritual posible del niño. A su vez, ello supone, como requisito sine qua non, el pleno respeto a sus derechos fundamentales. En la misma línea, los padres, actores prioritarios en el proceso de crecimiento y realización de sus hijos, deben orientar sus acciones y decisiones en tal sentido. Este deber paterno, así como la especial vinculación entre el interés superior del niño y el Bien Común, han sido expresamente recogidas por el legislador en el artículo 222 inciso $2^{\circ}$ del Código Civil, antes transcrito ${ }^{125}$, el cual obliga a los padres a procurar la "mayor realización espiritual y material posible” del niño como forma de servir a su interés superior.

La estrecha vinculación entre los dos conceptos indicados es virtuosa, toda vez que permite armonizar, sino todos, al menos la mayor parte de los contenidos del interés superior del niño antes mencionados (e.g., beneficio a largo plazo del niño; bienes necesarios para su desarrollo integral; pleno aprovechamiento de las potencialidades). Otras ventajas de adoptar esta postura es que nos permite trabajar con un concepto (Bien Común), cuyo contenido no es ajeno a nuestra doctrina y jurisprudencia. Más aún, nos ayuda a conjurar dos de los grandes problemas que detectamos en algunas de las definiciones antes vistas, cuales son un extremo individualismo y la pretensión de absoluto. Ambos temas están íntimamente relacionados y dicen relación con una suerte de "santificación" del interés superior del niño, en virtud del cual se lo considera como el fin prioritario y dominante en cualquier situación concebible. Ello supone el riesgo de

125 GLENDON (1998). 
poner al niño en cuestión, su individualidad, por sobre la de cualquier otra persona, incluso de otros niños. Paralelamente, construye el concepto en términos tan absolutos e hiperindividualistas ${ }^{126}$ que rompe con el principio básico en materia de derechos fundamentales, y es que ninguna prerrogativa, derecho o principio rige siempre y en toda circunstancia (incluso el derecho a la vida admite excepciones, tales como la legítima defensa).

Frente a estos riesgos, resulta muy útil la contextualización del interés superior del niño en relación al Bien Común. Es así como toda decisión respecto de un niño debe considerar no solo los efectos que tendrá sobre el mismo, sino también sobre el resto de la sociedad, y particularmente sobre otras personas, adultos o niños. Una cosa es que los niños requieran atención especial del Estado y de la sociedad, y otra que ello se traduzca en una preferencia automática en toda situación al punto de vulnerar las bases mismas del valor-principio-derecho de la igualdad. Ello se aplica particularmente en aquellas situaciones en que se configurarían conflictos de derechos entre el niño y otros individuos, dotados de la misma dignidad y derechos que aquel ${ }^{127}$.

Quisiéramos concluir esta sección con una advertencia. Si bien sostenemos que adoptar el interés superior del niño como finalidad de la intervención o asistencia paterna parece no solo razonable, sino que se encuentra en la línea del actual desarrollo del derecho internacional y comparado, ello no significa que nos parezca un concepto carente de problemas. Algunos de ellos ya han sido mencionados (individualismo exacerbado y pretensión de absoluto), pero falta aún considerar el potencialmente más peligroso. Nos referimos a la posibilidad de que el interés superior del niño se convierta en un título de intervención estatal en la realidad familiar extremadamente flexible ${ }^{128}$. En efecto, no cabe duda que la finalidad en cuestión conlleva una importante dosis de subjetividad $^{129}$, por lo que es perfectamente probable que el Estado (léase juez, legislador o administrador), discrepe de la interpretación que al efecto están realizando los padres. En este contexto, será determinante el procedimiento que se establezca, idealmente por el legislador, para resolver tales diferencias de criterio. Aquel debe contener las salvaguardas que impidan la indebida intromisión en la vida familiar, pero a la vez permitir un control no solo nominal de las decisiones paternas. Volveremos a este punto hacia el final del artículo.

126 LATHRop (2007) pp. 10-11; ZERMATTEN (2003) pp. 7 y 8, y CORTE Suprema (2006) rol No 65532005, considerando Sexto. Nos parece que una visión diversa puede encontrarse en Cillero (2008) p. 138; COUSO (2006) p. 147; y Cillero (1999) pp. 8 y ss. Algo similar parece asumir LinACERO (2001) pp. 54 ss, y AGUILAR (2008) p. 239. Consideramos que parte de la discusión a este respecto se debe a una comprensión errada del "principio de protección especial", en virtud del cual los menores exigirían una mayor protección y diligencia estatal en el ejercicio de sus derechos. Ello, sin embargo, no implica que los derechos del menor primen por sobre aquellos de otras personas.

127 ZERMATTEN (2003) pp. 7 y 8. Una preocupación similar, pero más centrada en el niño que en la familia, puede hallarse en Couso (2006) p. 147 y en Cillero (2008).

128 GÓMEZ DE LA TORRe (2000) p. 24 y ZERMATTEN (2003) p. 12.

129 Sobre diversas concepciones de proporcionalidad, ClaYTON (2002) y BARNES (1998). En Chile, consultar FERMANDOIS (2006) pp. 169 y ss.; ALDUNATE (2008) pp. 264 y ss., y en materia tributaria FERNÁNDEZ (2000). 


\section{c) La proporcionalidad}

Complementando la importancia cardinal de la finalidad de la intervención sobre los derechos de los niños antes desarrollada, nos parece evidente la necesidad de establecer ciertos parámetros objetivos adicionales a las potestades paternas. Ellos servirán para el control judicial del ejercicio de tales facultades.

En concreto, proponemos la aplicación atenuada del principio de proporcionalidad, lo cual exige:

i) Un vínculo de causalidad directa entre la finalidad invocada y el acto específico de intervención.

ii) Que la intervención no redunde en el perjuicio del niño. Ello debe entenderse fundamental, pero no exclusivamente, como la vulneración de sus derechos, cuestión que per se se opondría al interés superior del niño.

Cabe recordar aquí que en algunas jurisdicciones la proporcionalidad exige, adicionalmente, que no exista otro medio de lograr la finalidad en cuestión que sea menos oneroso para los derechos involucrados y que el perjuicio para el derecho involucrado no sea excesivo ${ }^{130}$. Creemos, sin embargo, que estos requerimientos no debieran aplicarse en el contexto en estudio por diversas razones. En primer término, porque aquellos permiten una intervención judicial mucho más vasta e intensa, la cual nos parece incompatible con la protección constitucional de la familia y los derechos-deberes de los padres antes invocados. En segundo lugar, se trata de requisitos que nos parecen impracticables en el contexto de las decisiones sobre los hijos. Aquellas son tantas y de tal frecuencia, que hacen imposible realizar un análisis previo tan sofisticado en cada caso. En contraste, los dos requisitos que propusimos previamente son mucho más simples de cumplir gracias a una sencilla y cuasiinstantánea reflexión que linda con el sentido común. En tercer lugar, consideramos que las situaciones más graves que pudieran evitar estos requerimientos adicionales son perfectamente controlables bajo la segunda exigencia propuesta en relación a la finalidad del interés superior del niño. Así, por ejemplo, si para evitar una gangrena los padres deciden amputar un brazo, en circunstancias que la mutilación de la mano sería suficiente, dicha decisión claramente irrogaría un perjuicio al niño que se opondría directamente a su mejor interés.

\section{d) Excepcionalidad e interpretación a lo menos estricta}

Debemos considerar que la intervención paterna en el ejercicio de los derechos fundamentales de sus hijos es, como toda injerencia sobre esa clase de derechos, excepcional. En consecuencia, la interpretación que debe otorgarse a las facultades de los padres en estas materias debe ser estricta, o incluso restringida, y no deben extenderse más allá de los supuestos de hecho que la originan (i.e., inmadurez del niño).

130 Algunos van más lejos y plantean derechamente una presunción de suficiente entendimiento por parte de los adolescentes, e.g., BrUGUeras (2004) p. 32. 
Excepcionalidad no debe confundirse con infrecuencia. Los padres deben adoptar decenas y hasta cientos de decisiones en estas materias, y ello es legítimo y necesario para el derecho. Sin embargo, eso no significa que la situación sea "normal". Por el contrario, se trata de circunstancias que escapan a la regla general, pero que pueden mantenerse en el tiempo, tal y como lo entendemos con los incapaces en Derecho Civil.

Algunas consecuencias de lo anterior son las siguientes:

i) En caso que el niño tenga capacidad real de decisión (i.e., capacidad natural) para consentir un tratamiento médico, debe estarse a su voluntad y no a la de los padres. Ello se vincula estrechamente al principio de realidad en materia de derechos fundamentales y al principio evolutivo antes estudiado. En otras palabras, si el niño ya alcanzó el grado de madurez suficiente para ejercer sus derechos fundamentales, aun cuando no se hayan cumplido debidamente ciertos requisitos meramente formales (e.g., límite de edad), debe cesar la interferencia paterna en ese contexto ${ }^{131}$. En este caso, la voluntad del niño debe ser respetada aun cuando no parezca seguir la opción más razonable, o incluso si no expresa razones suficientes para ello, tal y como se procede con los adultos en materia de tratamiento médico ${ }^{132}$.

ii) En caso de duda, debe entenderse que el niño es capaz de decidir acerca de su tratamiento médico. Ciertamente, el contexto será fundamental, en particular las consecuencias de la decisión, toda vez que a mayor gravedad de aquellas, más certeza se requerirá de las facultades del niño. Complementamos lo anterior señalando que cuando nos referimos a "duda", estamos entendiendo que existe más que una simple y abstracta sospecha o indicio. En efecto, el punto es que habiendo tomado todos los factores en consideración (e.g., edad, consecuencias de la decisión, claridad de la expresión de la voluntad del niño, comprensión de los posibles efectos), no existe convencimiento pleno de que el niño pueda ejercer su derecho a consentir en propiedad.

iii) Si el niño ha adoptado decisiones en materia de consentimiento médico en el pasado, en razón de que se le consideró suficientemente maduro para ello, debe considerársele igualmente capaz y maduro en las situaciones posteriores que se presenten. Ello siempre y cuando se trate de materias similares o de menor relevancia, particularmente en cuanto a sus efectos, cuestión que deberá analizarse en el contexto específico de que se trate. Así, por ejemplo, que un niño sea considerado capaz para decidir sobre una operación de adenoides no implica que sea igualmente autónomo para someterse a un tratamiento experimental contra el cáncer o a una vasectomía.

\footnotetext{
${ }^{131}$ La irracionalidad en la decisión del menor podría, según algunos, justificar la interferencia de otros en sus decisiones. FREEMAN (2006) p. 272.

132 E.g., PACHeco (2001) pp. 156-158; Burdiles (2004) pp. 97 y 98; BórQuez et al. (2004) pp. 12431244; Beauchamp y Childress (2001) pp. 77 y ss.; Maglio (2001) p. 37; Murúa (2000) pp. 7 y 8; Código de Ética Colegio Médico De Chile (2008) en sus artículos 24 a 28 y el Decálogo de Buena Práctica Médica, Colegio Médico de Chile (2009) No 3.
} 
iv) No puede, otorgarse las mismas prerrogativas de intervención de los padres a los representantes legales. Estos últimos carecen de los fundamentos constitucionales y naturales que justifican las potestades paternas en estas materias (y es muy discutible que compartan siquiera los fundamentos civiles de tales facultades). Por tanto, en caso de ausencia de los padres, creemos necesario la creación legal de un guardián específicamente encargado del bienestar e interés superior del niño, el cual se encuentre excluido del manejo y administración de su patrimonio, y que responda, en lo posible, a relaciones reales de familia.

\section{OTRAS CONSIDERACIONES RELEVANTES}

\section{PROCEDIMIENTO ADECUADO}

Es necesario comprender que la decisión final no es lo único que se encuentra en juego cuando hablamos de tratamientos médicos de niños. En efecto, aun cuando no se permita al niño resolver la materia, aquel posee otros derechos que deben ser respetados en el procedimiento que permite alcanzar la decisión final. Nos parece que los más relevantes serían los siguientes:

a) Derecho a ser informado. En términos generales, comprende entregar las herramientas necesarias para poder comprender, según su grado de madurez, la situación de su salud, así como las opciones de tratamiento y las consecuencias de dichas alternativas. Durante la aplicación del tratamiento, el niño debe ser convenientemente informado del desarrollo del mismo y su conformidad o disconformidad a lo esperado. Finalmente, el niño debe conocer las consecuencias efectivas del tratamiento realizado así como las opciones que pudiesen abrirse a continuación. Diversos autores han profundizado en las características y modalidades de este derecho y de la información que comprende ${ }^{133}$.

b) Derecho a ser adecuadamente aconsejado. El niño deber ser ilustrado acerca de la alternativa más conveniente para su caso. Por tanto, no se trata solo de entregarle información, sino de comunicarle juicios de valor sobre dicha información. Los sujetos pasivos de esta obligación son tanto los padres como los médicos tratantes.

c) Derecho a expresarse o a ser escuchado ${ }^{134}$, cuestión que a nuestro juicio excede solo de opiniones y alcanza a todo tipo de manifestaciones, incluidas aquellas de sentimientos, emociones, incluso reacciones incoherentes o irracionales, etc. ${ }^{135}$. Resulta importante entender a este respecto que los niños siempre pueden expresarse, cualquiera sea su edad, si bien la forma de hacerlo puede no identificarse con aquellas propias de los adultos. Esta realidad es un hecho evidente para la

133 Lathrop (2007) pp. 14-19 y (2004). GÓMEZ DE LA TORRE (2000) p. 26 lo considera una aplicación del interés superior del niño.

134 A este respecto resulta interesante el comentario sobre la Children's Act inglesa de 1989 en Couso (2006) p. 153.

135 Berro (2001) p. 45; Decálogo de Buena Práctica Médica Colegio Médico de Chile (2009) No 2. 
experiencia médica ${ }^{136}$, y goza de protección jurídica explícita en la Convención (artículos 12 y 13).

d) Derecho a que su opinión sea tomada en cuenta. Si bien la decisión final puede ser diversa a la deseada por el niño, las preferencias de este último deben ser debidamente consideradas dentro del proceso de decisión de los padres. Este elemento, reconocido tanto por la Convención (artículo 12) como por el Código de Ética del Colegio Médico de Chile (artículo 27), es de la mayor importancia y se relaciona directamente a la dignidad e integridad psíquica y emocional del niño. Su desconocimiento, por tanto, "implica un acto de extrema violencia: la violenta experiencia de que su vida [del niño] se decida por personas que lo conocen y que no demuestran tener interés en tomar en cuenta lo que le pasa" ${ }^{137}$. Más aún, la opinión del niño otorgará información relevante para una más precisa identificación del interés superior del niño en el caso en cuestión ${ }^{138}$.

Adicionalmente, el procedimiento de toma de decisión debe responder al ya comentado principio evolutivo, ya que un adolescente tendrá mayor necesidad, pero también mayor capacidad, de expresión de sus opiniones y sentimientos ${ }^{139}$. La participación del niño, por tanto, se debe ir ampliando en la medida que este va madurando y haciéndose capaz de ejercer sus derechos fundamentales personalmente. Para ello, es necesario asociar estrechamente la participación con la responsabilidad que el niño asume en la decisión final. En este contexto, particularmente problemática puede ser la negativa del niño a participar en el proceso de toma de decisión. En efecto, los derechos antes enunciados son prerrogativas del niño que este podría no querer ejercer, obligando a padres, médicos y jueces a obrar y decidir sin ellos ${ }^{140}$. Ciertamente esta solución, si bien necesaria, dista de ser deseable, por cuanto impide al niño su progresivo involucramiento en las decisiones que le atañen, a la vez que arroja un resultado que es completamente ajeno a su principal afectado.

\section{SOLUCiÓN DE CONFLICTOS}

Es evidente que la situación ideal en materia de tratamiento médico de un niño es que converjan los consentimientos tanto del aquel como de sus padres, así como la opinión de los médicos. El problema surge cuando ello no ocurre, sea porque el niño se enfrenta a la voluntad de sus padres, o porque estos no se ponen de acuerdo entre sí, o incluso porque el médico no acepta la voluntad de hijos y/o padres.

Sobre la base de los principios y reflexiones expuestos previamente en este trabajo, sostenemos el siguiente conjunto de reglas y criterios para solucionar estos conflictos:

\footnotetext{
136 Couso (2006) p. 154.

137 COUSO (2006) p. 149.

138 LATHROP (2004) p. 209.

139 RUEDA (2008) p. 12.

140 BERRO (2001) p. 47. Así también se reconoce en ciertas legislaciones extranjeras, donde incluso el juez puede verse imposibilitado de imponer su voluntad al menor. Un caso interesante es el caso de Inglaterra y su Children Act 1989.
} 
a) Si el niño ha logrado suficiente capacidad natural para comprender la decisión que debe tomar y las consecuencias de la misma, su consentimiento debe ser el determinante, incluso por sobre la voluntad de los padres ${ }^{141}$. A mayor seriedad de las consecuencias del tratamiento o ausencia de él, mayor debe ser el grado de madurez exigido. En caso de existir un límite de edad legalmente establecido para estos efectos, aquel debe operar como una presunción simplemente legal de la capacidad o incapacidad natural del niño.

b) Respecto de quién determina si la capacidad natural del niño es suficiente, nos parece que la solución constitucionalmente más apropiada es que lo hagan los padres, en virtud de su deber-derecho de cuidado y asistencia, así como de la naturaleza eminentemente -si bien no exclusivamente- familiar de estos temas. A la inversa, nos parece ser lo más adecuado que se deje esta decisión a los médicos. Si bien la práctica nacional y comparada demuestra que los facultativos han comenzado a asumir estas determinaciones ${ }^{142}$, nos parece que ello es incorrecto, toda vez que les significa asumir, si bien puntualmente, un rol de protección y cuidado que nuestro ordenamiento jurídico ha entregado a los padres.

c) Si el niño no goza de la necesaria capacidad natural, son los padres quienes deben consentir al tratamiento médico.

d) Tanto la decisión de los padres acerca del tratamiento médico, como aquella sobre la capacidad o incapacidad natural del hijo, deben ser susceptibles de ser impugnadas judicialmente, a lo menos por el niño y los doctores tratantes ${ }^{143}$. Los derechos del niño durante el procedimiento de adopción de la decisión tampoco pueden ser preteridos. El principio rector en esta materia debe ser el interés superior del niño. En efecto, creemos que las obligaciones que tanto nuestra Constitución (artículos $1^{\circ}, 5^{\circ}, 19$, entre otros) como la Convención y otros tratados internacionales imponen al Estado en materia de protección de derechos fundamentales, unidas a las facultades conservadoras de nuestros tribunales de justicia ${ }^{144}$, obligan a la intervención de los mismos frente al riesgo de vulneración de los derechos de los niños ${ }^{145}$.

141 Bórquez et al. (2004) p. 1245; Correa y VALdivia (2001) pp. 51 y ss., y SÁNCHEZ (1996) pp. 9-10. El artículo 27 del Código de Ética del Colegio Médico demuestra la preocupación del gremio en tal sentido, al señalar que: "La opinión del menor de edad deberá ser considerada, atendiendo a su edad y grado de madurez”. Colegio Médico DE Chile (2008).

142 E.g., MaGLio (2001) p. 38. Garduño considera que "el pediatra es en general, una persona muy cercana al niño, quien más capacitado está para comprender objetivamente lo que más conviene; nadie puede tener un juicio mejor que el suyo cuando el bienestar, la salud y al vida están en juego" GARDUÑO et al. (2001) p. 110. Si bien no dice expresamente que el médico debe decidir, su argumentación lo sitúa a un paso de dicha afirmación.

143 Aquellas que tienen por objeto "velar porque las garantías individuales consagradas en la Constitución Política sean respetadas" CASSARINO (1998) p. 63. También Silva (2002) p. 150.

${ }^{144}$ Cabe cuestionarse cuál es el alcance de estas facultades de los tribunales, y si su competencia sobre los niños puede, dado el caso, extenderse más allá de aquella confiada a los padres. Ilustrativo a este respecto es caso de las siamesas Jodie y Mary Attard, resuelto por la Corte de Apelaciones de Inglaterra. HARVARD LAW REVIEW ASSOCIATION (2001).

145 E.g., ZERMATTEN (2003) p. 25; Gracia (1997) pp. 96-97, y BRUGUERAS (2004) pp. 22 y ss; FrEEMAN (2006) p. 257. 
e) Dado que el interés superior del niño se puede convertir en un título de intervención estatal extremadamente poderoso, y por tanto peligroso para la familia, creemos que la impugnación judicial debe someterse a ciertos condicionamientos, idealmente regulados por el legislador:

i) Presunción simplemente legal de que los padres conocen y persiguen siempre el interés superior del niño. La literatura revisada nos ofrece diversas razones para ello, e.g., son quienes más conocen al niño; siempre debieran desear lo mejor para sus hijos; son ellos quienes más lo quieren y por tanto van a sufrir más directamente -excluyendo al niño- las consecuencias de su decisión (e.g., emocionales, financieras, etc.); estas decisiones se vinculan directamente a la intimidad de la familia; entre otras ${ }^{146}$.

ii) Los criterios de control usados por el juez para analizar la decisión paterna deben ser los condicionamientos a la misma presentados más arriba, vale decir, el principio evolutivo o de desarrollo progresivo; el interés superior del niño como finalidad última; la proporcionalidad de la decisión paterna y la excepcionalidad de la intervención de los padres en el ejercicio de los derechos del hijo. Del mismo modo, el juez debe considerar el procedimiento seguido y cuánto se ha incorporado y considerado al niño en el mismo. Algunos de estos criterios serán más aplicables cuando se impugna la calificación de madurez del niño (e.g., principio evolutivo), y otros cuando se ataca la decisión misma de los padres frente al tratamiento médico (e.g., proporcionalidad).

Existen autores que, al referirse a las decisiones judiciales en esta materia, imponen ciertas reglas adicionales al tribunal. Así, por ejemplo, se debería fallar siempre a favor de preservar la vida; o apoyar en toda circunstancia a la parte (niño o padres) que sí quiere acceder al tratamiento médico; o afirmar siempre la imposibilidad de rechazar el tratamiento si ello va a producir la muerte, etc. ${ }^{147}$. A nuestro juicio, estas reglas no pueden considerarse como absolutas (no obstante la gran fuerza constitucional de algunas, especialmente de la primera de ellas), y debieran subsumirse en los criterios antes analizados, particularmente en la finalidad rectora del interés superior del niño.

iii) Dentro del marco antes indicado, consideramos que el juez debe guardar deferencia a la decisión de los padres, independientemente que considere que existen otras alternativas mejores (por ello rechazamos más arriba la aplicación de una proporcionalidad completa, i.e., aquella que analiza la existencia de otros medios menos onerosos para el ejercicio del derecho). En otras palabras, el juez debe ser solo un contralor de casos evidentes, dejando el resto en las manos de los padres.

f) Finalmente, destacamos que una serie de consideraciones mencionadas previamente en este trabajo hacen imprescindible un análisis caso a caso. Algunas de ellas son las siguientes:

146 CORREA y VALDivia (2001) pp. 71-72. 
i) El principio evolutivo y la fabilidad de los límites rígidos de edad;

ii) La naturaleza esencialmente contextual del interés superior del niño, o al menos de su aplicación;

iii El principio de realidad y efectividad de los derechos fundamentales;

iv) La entidad de las consecuencias de la decisión específica;

v) El carácter excepcional de la intervención paterna, y

vi) La necesidad de conjugar, en cada situación, el interés superior del niño, las obligaciones estatales y el respeto a la familia.

\section{CONCLUSIONES}

1. Resulta imprescindible desarrollar un marco constitucional que regule con claridad la situación de los tratamientos médicos en niños, delimitando los derechos, obligaciones, principios y criterios aplicables en relación a los niños, sus padres, los médicos y el juez. La situación jurídica actual, fundamentada en normas del Derecho Civil e Internacional, así como en la práctica médica, es inadecuada e insuficiente.

2. Los tratamientos médicos no consentidos suponen una intervención severa en el ejercicio de los derechos fundamentales del niño, tales como el derecho a la vida, la integridad física y psíquica, la privacidad, la libertad de conciencia y la igualdad. Tales intervenciones deben, a lo menos, sujetarse a las reglas generales en materia de interferencia de derechos fundamentales (e.g., establecimiento por ley, proporcionalidad).

3. Los niños tienen el derecho a ser asistidos en el ejercicio de sus derechos fundamentales, labor que corresponde en primerísimo lugar a los padres. Así se desprende de la misma naturaleza del ser humano en desarrollo; del reconocimiento constitucional de la familia, entidad preferentemente llamada a dar protección y velar por el desarrollo de sus miembros, y del Derecho Internacional especializado.

4. Las facultades paternas en relación a los tratamientos médicos de sus hijos reconocen diversas condicionantes o limitaciones, destacando:

a) El principio evolutivo: la paulatina maduración de los niños les permite ir ejerciendo sus derechos progresivamente por sí mismos, hasta llegar al punto en que la intervención paterna se vuelve redundante e ilegítima. Crucial en esta materia son el concepto de capacidad natural y sus indicadores.

b) La finalidad de la intervención paterna debe ser siempre el interés superior del niño, debidamente contextualizado en nuestro concepto constitucional de Bien Común. Tal vinculación, reconocida expresamente por el legislador, hace más practicable su determinación y utilización, a la vez que conjura dos peligros potenciales del concepto: extremo individualismo y pretensión de absoluto.

c) La proporcionalidad, entendida solo como la causalidad directa entre la finalidad legítima invocada y el acto específico de intervención, siempre y cuando este no redunde en perjuicio del niño. Los otros elementos de la proporcionalidad nos parecen demasiado invasivos para la realidad familiar.

d) Excepcionalidad de la intervención paterna. Si el niño es capaz, o incluso en caso de duda acerca de su capacidad, debe tomar la decisión por sí mismo. 
5. Los representantes legales carecen de los fundamentos constitucionales que justifican las facultades paternas para decidir acerca de los tratamientos médicos de los niños, razón por la que no pueden gozar de similares prerrogativas. A falta de los padres, se requiere la creación legislativa de un guardián especial, excluido de la administración de su patrimonio, y que responda, en lo posible, a relaciones reales de familia.

6. Aun cuando el niño no adopte la decisión final sobre su tratamiento médico, el procedimiento seguido para resolver la cuestión debe reconocer sus derechos a ser informado, a ser adecuadamente aconsejado, a expresarse y ser escuchado, y a que su opinión sea debidamente tomada en consideración. Adicionalmente, a mayor madurez, mayor participación del niño en dicho procedimiento.

7. En caso de conflicto entre el niño-paciente, sus padres y los médicos tratantes, debe estarse a la voluntad del primero si goza de la suficiente capacidad natural, de lo contrario deben decidir los padres, pero nunca los médicos. La evaluación de madurez la realizan en primer término los padres. Las decisiones de estos últimos deben ser siempre susceptibles de revisión en sede judicial, mediante un análisis caso a caso. La regla general, sin embargo, debe ser la deferencia del juez hacia los padres, reconociéndose una presunción simplemente legal de que estos siempre persiguen el interés del niño.

8. No postulamos la eliminación del rol que los padres ejercen en estas materias, sino su reformulación desde la perspectiva constitucional, otorgándole mayor solidez jurídica y coherencia con las normas y principios constitucionales sobre derechos fundamentales.

\section{BIBLIOGRAFÍA}

Aguilar Cavallo, Gonzalo (2008): “El Principio del Interés Superior del Niño y la Corte Interamericana de Derechos Humanos" en Estudios Constitucionales, Año 6 No 1: pp. 223-247.

AldunAte Lizana, Eduardo (2008): Derechos Fundamentales (Santiago, LegalPublishing) $439 \mathrm{p}$.

Alessandri Rodríguez, Arturo; Somarriva Undurraga, Manuel y Vodanovich Haklicka, Antonio (1998): Tratado de Derecho Civil. Partes Preliminar y General (Santiago, Editorial Jurídica de Chile) Tomo II.

Álvarez VÉlez, María Isabel (1994): La Protección de los Derechos del Niño (Madrid, Universidad Pontificia Comillas) 205 pp.

BAEZa Concha, Gloria (2001): “El Interés Superior del Niño: Derecho de rango Constitucional, Su Recepción en la Legislación Nacional y la Aplicación en la Jurisprudencia” en Revista Chilena de Derecho, vol. 28 No 2, pp. 355-362.

BARNES, Javier (1998): "El principio de proporcionalidad. Estudio preliminar", en Cuadernos de Derecho Público, No 5: pp. 15-49.

Beauchamp, Tom y Childress, James (2001): Principles of Biomedical Ethics (5a ed., Nueva York, Oxford University Press) 454 p.

Berro Rovira, Guido (2001): "El consentimiento del adolescente: sus aspectos médicos, éticos y legales", en Archivos de Pediatría del Uruguay, vol. 72 No 1: pp. 45-49. 
Bórquez, Gladys; RAINieri, Gina y Bravo, Mireya (2004): "La evaluación de la "capacidad de la persona": en la práctica actual y en el contexto del consentimiento informado" en Revista Médica de Chile, vol. 132 No 10: pp. 1243-1248.

BRUgueras DíAZ, Marcela (2004): Los derechos del menor respecto de los tratamientos médicos, a la luz de la normativa constitucional, legal y comparada, tesis para optar al grado de Licenciado en Derecho en la Pontificia Universidad Católica de Chile, inédito (Santiago, PUC) 109 pp.

Burdiles, Patricio (2004): “Consentimiento informado en cirugía”, en Revista Chilena de Cirugía, vol. 56 No 2: pp. 97-98.

Cassarino Viterbo, Mario (1998): Manual de Derecho Procesal (5a ed., Santiago, Editorial Jurídica de Chile) Tomo I.

Cena Egaña, José Luis (2008): Derecho Constitucional Chileno. Derechos, Deberes y Garantías (2a ed., Santiago, Ediciones Universidad Católica de Chile) Tomo I.

Cea Egaña, José Luis (2004): Derecho Constitucional Chileno. Derechos, Deberes y Garantías (Santiago, Ediciones Universidad Católica de Chile) Tomo II.

Choper, Jesse H. et al. (2001): Constitutional Law (St. Paul, West Group) 1575 p.

Ciccone, Lino (2005): Bioética: Historia. Principios. Cuestiones (2a ed., Madrid, Ediciones Palabra) 478 p.

Cillero Bruñol, Miguel (2008): “El Interés Superior del Niño en el Marco de la Convención Internacional sobre los Derechos del Niño", en Justicia y Derechos del Niño (UNICEF), No 9: pp. 125-142.

Cillero Bruñol, Miguel (1999): Infancia, Autonomia y Derechos: Una Cuestión de Principios [Fecha de Consulta: 12 de enero de 2009]. Disponible en: www.iin.oea.org/sim/cad/sim/pdf/mod1/Texto\%203.pdf

Claro Solar, Luis (1925): Explicaciones de Derecho Civil Chileno y Comparado (Santiago, Imprenta Cervantes) tomo III.

Clayton, Richard (2002): "Proportionality and the Human Rights Act 1998: Implications for Substantive Review”, en Judicial Review, vol. 2 No 7: pp. 124-136.

COrRea Escobar, Carolina y VAldivia Barría, Javier (2001): El Contrato de Servicios Médicos (Santiago, Editorial ConoSur) 224 pp.

Couceiro, Azucena y Heredia, Fernando (2007): "Los Derechos de los Pacientes y el proyecto de Ley en Chile" en Vida Médica, vol. 59 No 1: pp. 66-73.

Couso, Jaime (2006): "El niño como sujeto de derechos y la nueva justicia de Familia. Interés Superior del Niño, Autonomía progresiva y derecho a ser oído”, en Revista de Derechos del Niño (UDP-UNICEF), No 3-4, pp. 145-166.

DíAZ DE VAldÉS JUliÁ, José Manuel (en prensa): “Tratamientos Médicos en Menores de Edad: Situación Actual y Claroscuros del Proyecto de Ley sobre los Derechos y Deberes en Relación a la Atención en Salud", ponencia en las XXXVIII Jornadas Chilenas de Derecho Público, organizadas por la Universidad de Concepción.

Domínguez Hidalgo, Carmen (2001): "La formación del consentimiento en la relación médico-paciente” en Boletín Científico de la ACHS, Año 3 No 5-6: pp. 16-25.

Evans de la CuAdra, Enrique (1999): Los Derechos Constitucionales (2a ed., Santiago, Editorial Jurídica de Chile) tomo II. 
FANlO CORTÉS, Isabel (2008): "Los Derechos del Niño y las Teorías de los Derechos: Introducción a un Debate", en Justicia y Derechos del Niño (UNICEF), No 9: pp. 159-176.

FELDman, David (2002): Civil Liberties and Human Rights in England and Wales (2a ed., New York, Oxford University Press) 1108 pp.

Fermandois VÖHringer, Arturo (2006): Derecho Constitucional Económico (2a ed, Santiago, Ediciones Universidad Católica de Chile) 333 pp.

FERNÁNDEZ GONZÁLEZ, Miguel Ángel (2008): "Reflexiones constitucionales en torno de los desafíos de la atención en la salud de niños y adolescentes", en Ars Medica, vol. 16 No 16 (online) [Fecha de Consulta: 30 de junio de 2009]. Disponible en: http:// escuela.med.puc.cl/publ/arsmedica/ArsMedica16/Reflexiones.html

Fernández GonZÁlez, Miguel Ángel (2001): Principio Constitucional de la Igualdad Ante la Ley (Santiago, LexisNexis) 352 pp.

FERnÁndez GonZÁlez, Miguel Ángel (2000): "Principios Constitucionales de proporcionalidad y Justicia en Materia Tributaria”, en Revista Chilena de Derecho, vol. 27 No 2: pp. 357-371.

Figueroa García-Huidobro, Rodolfo (2008): "Concepto de Derecho a la Vida”, en Ius et Praxis, vol. No 14, No 1: pp. 261-300.

Freeman, Michael D.A (2006): “Tomando más en Serio los Derechos de los Niños” en Revista de Derechos del Niño (UDP-UNICEF) No 3-4: pp. 251-279.

García LlerenA, Viviana (2001): "El mayor interés del incapaz como criterio para la toma de decisiones médico sanitarias. Una visión panorámica de las nuevas orientaciones en el derecho comparado", en Boletín Científico de la ACHS, Año 3 No 5-6: pp. 26-37.

GARduÑo Espinosa, Armando; ReYes LuCAS, Cristina; OrTiZ, Gabina (2001): "Consentimiento informado en pediatría. La autonomía del niño en discusión” en Revista Mexicana de Pediatría, vol. 68 No 3: pp. 108-111.

Glendon, Mary Ann (1998): “El Lenguaje de los Derechos”, en Estudios Públicos, No 70: pp. 77-150.

Gómez de la Torre Vargas, Maricruz (2000): “El Interés Superior del Niño", en Gaceta Jurídica, No 238: pp. 23-26.

Gracia Guillén, Diego (1997): "Bioética y Pediatría": pp. 87-100 [Fecha de Consulta: 30 de junio de 2009]. Disponible en: https://www.u-cursos.cl/medicina/2008/0/MFAHEM55/5/material_docente/objeto/196711

Jiménez García, Joel Francisco (2001): Derechos de los Niños (2a ed., México, Instituto de Investigaciones Jurídicas) $57 \mathrm{pp}$.

LATHrop GÓmEZ, Fabiola (2007): "Los Conflictos de Intereses entre progenitores e Hijos” en Gaceta Jurídica, No 330: pp. 7-30.

LATHrop GÓmeZ, Fabiola (2004): "El Derecho del niño a Ser Oído", en MARTinic, María Dora (coord.), Nuevas tendencias del Derecho (Santiago, LexisNexis) pp. 201 231.

LinaCero De la Fuente, María (2001): Protección Jurídica del Menor (Madrid, Montecorvo) $517 \mathrm{pp}$. 
MAGLIO, Ignacio (2001): "El derecho de los menores a participar del proceso de Consentimiento Informado", Infosida, Buenos Aires, Dirección de Sida, GCBA, No 1: pp. 37-39 (online) [Fecha de Consulta: 30 de junio de 2009]. Disponible en: www.sap.org.ar/staticfiles/publicaciones/correo/cor2_02/999.pdf

MASON, Mary Ann (2004): “¿Una Voz para el niño?”, en Revista de Derechos del Niño (UDP-UNICEF) No 2: pp. 115-137.

MCCRudden, Christopher (2008): "Human Dignity and Judicial Interpretation of Human Rights", en The European Journal of International Law, vol. $19 \mathrm{~N}^{\circ} 4$ : pp. 655-724.

Molina Guaita, Hernán (2006): Derecho Constitucional (6a ed., Santiago, LexisNexis) $511 \mathrm{pp}$.

MurúA, Alejandro (2000): "El Consentimiento Informado: algo más que un contrato" en Cuadernos de Cirugía, vol. 14 No 1: pp. 7-8.

PACHECo M., Isabel Margarita (2001): "El Consentimiento Informado: Una forma de entender la relación Médico-Paciente”, en Revista Médica, vol. 12 No 4: pp. 156-158.

Pavez Planas, Mónica (2004): El mejor interés del Niño y sus Derechos Constitucionales: Bases para la Toma de decisiones Médicas Respecto de la Mantención o Suspensión de tratamientos Médicos, tesis para optar al grado de Licenciado en Derecho en la Pontificia Universidad Católica de Chile, inédito (Santiago, PUC) 168 pp.

Ramos Pasos, René (2001): Derecho de Familia (4a ed., Santiago, Editorial Jurídica de Chile) Tomo I.

Retamales P., Avelino (2003): "Lecciones que Dejan los pacientes Adultos que rechazan Transfusiones de Sangre a Partir de la Doctrina de Nuestros tribunales", en Ius Publicum, No 11: pp. 75-102.

RIVAS, Pedro y SERnA, Pedro (2001): “¿Debe una Sociedad Liberal Penalizar la Eutanacia? Consideraciones en torno al argumento de la autonomía de la voluntad” en Revista de Derecho, Universidad de la Santísima Concepción, No 9: pp. 285-299.

ROA, Armando (1998): Posthumous work of the famous Chilean psychiatrist. A comprehensive vision from the classic and christian fundamentals of western ethics to the latest concerns (Santiago, Editorial Andrés Bello) 276 pp.

Rueda Castro, Laura (2008): "Consentimiento informado en niños y adolescentes" [Fecha de Consulta: 30 de junio de 2009]. Disponible en: https://www.u-cursos.cl/ medicina/2007/0/TOMINNI4/1/material_docente/objeto/147886

SÁNCHEZ GonZÁleZ, Miguel Ángel (1996): "El Consentimiento Informado: un derecho del enfermo y una forma distinta de tomar las decisiones", Cuadernos del Programa Regional de Bioética, No 2 [Fecha de Consulta: 30 de junio de 2009]. Disponible en: http://www.colmed2.org.ar/images/code02.pdf

SANCHO GALlargo, Ignacio (2004): “Tratamiento legal y jurisprudencial del consentimiento informado" [Fecha de Consulta: 30 de junio de 2009]. Disponible en: www.indret.com/pdf/209_es.pdf

Silva BASCuñán, Alejandro (2008): Tratado de Derecho Constitucional (2a ed., Santiago, Editorial Jurídica de Chile) Tomo XII.

Silva Bascuñán, Alejandro (2006): Tratado de Derecho Constitucional (2a ed., Santiago, Editorial Jurídica de Chile) Tomo XI. 
Silva BASCuÑán, Alejandro (2002): Tratado de Derecho Constitucional (2a ed., Santiago, Editorial Jurídica de Chile) tomo VIII.

Silva BASCuñán, Alejandro (1999): Tratado de Derecho Constitucional (2a ed., Santiago, Editorial Jurídica de Chile) tomo IV.

Ugarte Godoy, José Joaquín (2006): El Derecho de la Vida: El Derecho a la Vida Bioética y Derecho (Santiago, Editorial Jurídica de Chile) 598 pp.

VÁsquez VetTerlein, Mónica (2002): “Los Derechos del Niño Enfermo Terminal” en Derecho Público Contemporáneo, Año 3, No 7: pp. 43-66.

VillaVicencio Miranda, Luis (2008): “¿Derechos humanos para Quiénes? Reflexiones Sobre Algunas Cuestiones Embarazosas", en Revista de Derecho, vol. XXI, No 2: pp. 33-51.

Williams, Jaime (1999) Lecciones De Introducción Al Derecho (3a ed., Santiago, Editorial Fundación de las Ciencias Humanas) 458 p.

Zermatten, Jean (2003): El interés Superior del Niño. Del Análisis literal al Alcance Filosófico, informe de trabajo [Fecha de Consulta: 1 de julio de 2009]. Disponible en: http://www.childsrights.org/html/documents/wr/2003-3_es.pdf

\section{JURISPRUDENCIA}

\section{NACIONAL}

Corte de Apelaciones de Copiapó (2008): rol No 230-2008, Recurso de Protección, 9 de agosto de 2008.

Corte de Apelaciones de Puerto Montt (2008): rol No 172-2008, Recurso de Protección 18 de noviembre de 2008.

Corte de Apelaciones de Rancagua (2008): rol No 1034-2007, Recurso de Protección, 11 de febrero de 2008.

Corte de Apelaciones de Rancagua (2002) rol No 2292-2002, Recurso de Protección, 10 de diciembre de 2002.

Corte de Apelaciones de SAn Miguel (2008): rol No 104-2008, Recurso de Protección, 19 de abril de 2008.

Corte de Apelaciones de Santiago (2004): rol No 4105-2004, Cuarta Sala, 1 de septiembre de 2004.

Corte de Apelaciones de SAntiago (1994): rol No 846-1994, Recurso de Protección, 23 de marzo 1994.

Corte de Apelaciones de Santiago (1993): rol No 983-1993, Recurso de Protección, 31 de mayo de 1993.

Corte de Apelaciones de Temuco (2007) rol No 1848-2007, Recurso de Protección, Segunda Sala, 4 de diciembre de 2007.

Corte Suprema (2008): rol No 6419-2008, Cuarta Sala, 31 de diciembre de 2008.

Corte Suprema (2006): rol No 6553-2005, Cuarta Sala, 2 de noviembre de 2006.

Tribunal Constitucional (2008): rol No 740, 18 de abril de 2008. [Fecha de Consulta: 15 de julio de 2009]. Disponible en: http://www.tribunalconstitucional.cl/ index.php/sentencias/view/914 
Tribunal Constitucional (2008) rol No 914, 24 de enero de 2008 [Fecha de Consulta: 15 de julio de 2009]. Disponible en: http://www.tribunalconstitucional.cl/ index.php/sentencias/view/796

\section{COMPARADA E INTERNACIONAL}

Comisión Europea de Derechos Humanos (1976): X v. Island application No 6825 de 18 de mayo de 1976 [Fecha de Consulta: 7 de julio de 2009]. Disponible en: http:/ / cmiskp.echr.coe.int/tkp 197/portal.asp?session Id=26374851\&skin=hudocen\&action=request

Corte Interamericana de Derechos Humanos (2005): Caso de las Niñas Yean y Bosico vs. República Dominicana, sentencia de 8 de septiembre de 2005 [Fecha de Consulta: 30 de julio de 2009]. Disponible en: http://www.corteidh.or.cr/docs/casos/ articulos/seriec_130_esp.pdf

Corte Interamericana de Derechos Humanos (2003): Bulacio vs. Argentina, Sentencia de 18 de septiembre de 2003 [Fecha de Consulta: 30 de julio de 2009]. Disponible en: http://www.corteidh.or.cr/docs/casos/articulos/seriec_100_esp.pdf

Corte Interamericana De Derechos Humanos (2002): Opinión Consultiva OC17/2002 de 28 de agosto de 2002, solicitada por la Comisión Interamericana de Derechos Humanos [Fecha de Consulta: 07 de julio de 2009]. Disponible en: http:// www.corteidh.or.cr/docs/opiniones/seriea_17_esp.pdf

\section{OTRAS FUENTES}

Colegio Médico De Chile (2009): Decálogo de Buena Práctica Médica [Fecha de Consulta: 1 de julio de 2009]. Disponible en: http://www.colegiomedico.cl/ Default.aspx?tabid=145

Colegio Médico De Chile (2008): Código de Ética [Fecha de Consulta: 29 de julio de 2009]. Disponible en: http://www.colegiomedico.cl/Portals/0/files/etica/ 090305codigo_etica.pdf

Concilio VatiCANo II (1965): Constitución Pastoral Gaudium et Spes sobre la Iglesia en el Mundo Actual, 7 de diciembre de 1965 [Fecha de Consulta: 30 de julio de 2009]. Disponible en: http://www.vatican.va/archive/hist_councils/ii_vatican_council/documents/vat-ii_const_19651207_gaudium-et-spes_sp.html

Harvard Law Review Association (2001): "English Law. Court of Appeal Authorizes Surgical Separation of Conjoined Twins Although Procedure Will Kill One Twin. Re A (Children) (Conjoined Twins: Surgical Separation), [2000] 3 F. C. R. 577 (C. A.)" en Harvard Law Review, Vol. 114 No 6: pp. 1800-1806.

Historia De LA LEY 19.585 (1998): Modifica el Código Civil y otros cuerpos legales en materia de filiación, Segundo Trámite Constitucional, sesión No 16 de 22 de julio de 1998, informe complementario de la Comisión de Constitución Legislación, Justicia y Reglamento recaido en el proyecto de ley de la Honorable Cámara de Diputados que modifica el Código Civil y otros cuerpos legales en materia de filiación (1060-07) [Fecha de Consulta: 30 de julio de 2009]. Disponible en: http://www.bcn.cl/histley/lfs/ley19585/1375.pdf 
The National Commission for the Protection of Human Subjects of BioMedical AND Behavioral ReSEARCH (1979): Belmont Report, Ethical Principles and Guidelines for the Protection of Human Subjects of Research. [Fecha de Consulta: 15 de julio de 2009]. Disponible en: www.hhs.gov/ohrp/humansubjects/guidance/ belmont.htm

UniceF (2006): Convención sobre los Derechos del Niño. Las preguntas más frecuentes, actualizado el 15 de febrero de 2006 [Fecha de Consulta: 15 de julio de 2009]. Disponible en: http://www.unicef.org/spanish/crc/index_30229.html

Comisión de Estudio de una Nueva Constitución (1976): Actas Oficiales de la Comisión Constituyente, Tomo IV [Fecha de Consulta: 31 de julio de 2009]. Disponible en: http://www.bcn.cl/lc/cpolitica/constitucion_politica/Actas_comision_ortuzar/ Tomo_VI_Comision_Ortuzar.pdf 